Article

\title{
Experimental and Numerical Investigation of a MILD Combustion Chamber for Micro Gas Turbine Applications
}

\author{
Valentina Fortunato ${ }^{1,2, *}$, Andreas Giraldo ${ }^{3}$, Mehdi Rouabah ${ }^{1,3}$, Rabia Nacereddine ${ }^{3}$, \\ Michel Delanaye ${ }^{3}$ and Alessandro Parente ${ }^{1,2, *(\text { D }}$ \\ 1 Aero-Thermo-Mecanics Laboratory, École Polytechnique de Bruxelles, Université Libre de Bruxelles, \\ 1050 Bruxelles, Belgium; mehdi.rouabah@mitis.be \\ 2 Combustion and Robust Optimization Group (BURN), Université Libre de Bruxelles and Vrije Universiteit \\ Brussel, 1050 Bruxelles, Belgium \\ 3 MITIS SA, 4000 Liège, Belgium; andres.giraldo@mitis.be (A.G.); rabia.nacereddine@mitis.be (R.N.); \\ michel.delanaye@mitis.be (M.D.) \\ * Correspondence: Valentina.Fortunato@ulb.ac.be (V.F.); Alessandro.Parente@ulb.ac.be (A.P.); \\ Tel.: +32-2650-2671 (V.F.); +32-2650-2680 (A.P.)
}

Received: 9 October 2018; Accepted: 28 November 2018; Published: 1 December 2018

\begin{abstract}
In the field of energy production, cogeneration systems based on micro gas turbine cycles appear particularly suitable to reach the goals of improving efficiency and reducing pollutants. Moderate and Intense Low-Oxygen Dilution (MILD) combustion represents a promising technology to increase efficiency and to further reduce the emissions of those systems. The present work aims at describing the behavior of a combustion chamber for a micro gas turbine operating in MILD regime. The performances of the combustion chamber are discussed for two cases: methane and biogas combustion. The combustor performed very well in terms of emissions, especially $\mathrm{CO}$ and $\mathrm{NO}_{\mathrm{x}}$, for various air inlet temperatures and air-to-fuel ratios, proving the benefits of MILD combustion. The chamber proved to be fuel flexible, since both ignition and stable combustion could be achieved by also burning biogas. Finally, the numerical model used to design the combustor was validated against the experimental data collected. The model performs quite well both for methane and biogas. In particular, for methane the Partially Stirred Reactor (PaSR) combustion model proved to be the best choice to predict both minor species, such as $\mathrm{CO}$, more accurately and cases with lower reactivity that were not possible to model using the Eddy Dissipation Concept (EDC). For the biogas, the most appropriate kinetic mechanism to properly model the behavior of the chamber was selected.
\end{abstract}

Keywords: MILD combustion; fuel flexibility; $\mathrm{NO}_{\mathrm{x}}$ emissions; combustion model

\section{Introduction}

In the field of energy production, increasing attention needs to be paid to improving efficiency and reducing pollutants. To this end, especially for residential applications, micro-cogeneration systems seem very appealing. One of the most promising cogeneration technologies available nowadays is the micro-turbine which can provide a reasonable electrical efficiency of about $30 \%$, multi-fuel capability, low emission levels and heat recovery potential, and needs minimum maintenance [1]. Among the several options, micro gas turbines (mGT) are particularly interesting. Compared to the internal combustion engines, the main advantage of the mGT is lower emissions. As discussed by Abagnale et al. [2], it is also possible to integrate a cogenerative micro gas turbine with a solar panel array to facilitate the transition towards alternative energy sources. In order to further improve the efficiency and reduce the emissions of mGTs, it is necessary to carefully design the combustion 
chamber. Khidr et al. [3] compared different solutions to reduce the emissions of gas turbines. The authors believe that Moderate and Intense Low-Oxygen Dilution (MILD) combustion is the most promising approach to effectively reduce $\mathrm{NO}_{\mathrm{x}}$ and $\mathrm{CO}$ emissions. MILD combustion [4], also known as flameless [5] or High Temperature Air Combustion (HiTAC) [6], is able to provide high combustion efficiency with low $\mathrm{NO}_{\mathrm{x}}$ and soot emissions. MILD combustion needs the reactants to be preheated above their self-ignition temperature and enough inert combustion products to be entrained in the reaction region, in order to dilute the flame. The recirculation of the hot gases lowers the concentration of the reactants which reduces the reaction rates, thereby avoiding the formation of peaks of temperature [7]. Hence, $\mathrm{NO}_{\mathrm{x}}$ formation is suppressed as well as soot formation as a result of the lean conditions, low temperatures, and the large $\mathrm{CO}_{2}$ concentration in the exhausts. As reported by Dally et al. [8], the recirculation of the exhaust gases plays a fundamental role in MILD combustion, since it allows for a reduction in oxygen content and an increase in the temperature of the fresh gases. The recirculation can be both outside or inside the combustion chamber. Usually internal exhaust gas recirculation is achieved through special designs of the feeding jets as well as of the combustion chamber. Moreover, it has been found [3] that the exhaust gas recirculation promotes energy savings, since it preheats the reactants to a higher enthalpy and temperature. By doing so, preheating can extend the reactants flammability range to lower fuel equivalence ratios, therefore attaining lower fuel consumption. MILD combustion is also very stable and noiseless [9], so it is suited for gas-turbine applications [10] where conventional operations may lead to significant thermo-acoustic instabilities (humming) and stresses. Several studies have indeed shown that MILD combustion is well suited for gas turbines. A review of the literature about gas-turbine applications is reported by Arghode et al. [11]. Zornek et al. [12] investigated the performances of a flameless combustor in an mGT by equipping a Turbec T100 with a FLOX $($ combustion system, which is able to burn low-calorific value fuels. They demonstrated that the FLOX® burner enables stable operation and low pollutant emissions to be achieved over the whole operation range. The systems analyzed in the aforementioned works can provide an electric output of $100 \mathrm{~kW}$. There are also systems scaled down for even smaller electrical output, adapted for residential applications. The analysis of one of those mGTs operating in MILD mode has been presented by Seliger et al. [13]. The authors performed a detailed experimental characterization of the jet-stabilized combustor in order to investigate the influence of air preheating temperature, air-to-fuel ratio, and thermal power on the operation stability and emissions.

MILD combustion is recognized as a clean technology for fossil fuels but it can also represent an interesting solution to burn low calorific value fuels [14], high calorific industrial by-products, as well as hydrogen-enriched fuels [15]. Recently, Hosseini et al. [16] proved that the behavior of their flameless combustion chamber did not show significant changes when switching from natural gas to biogas. Similarly, Colorado et al. [17] proved that the mixing of the reactants above the auto-ignition temperature of the fuel, which is the main characteristic of the MILD regime, allows it to attain high fuel flexibility. Chen and Zheng [18] studied the MILD oxy-fuel combustion conditions up to commercial-scale for hydrogen-enriched biogas. They found that this regime can be stable even at relatively low preheating temperatures of the oxidant flow, extremely low oxygen content in the oxidizer and in presence of hydrogen in the fuel.

From a numerical point of view, the interaction between turbulent mixing and chemical kinetics in the MILD regime requires further investigation. Compared to the traditional combustion regime, turbulence levels are higher (because of the high momentum of the gases) which results in reduced mixing timescales; on the other hand, chemical timescales are slower by reason of the lower concentration of the reactants [19]. As a consequence, the Damköhler number approaches unity [20]. This implies that both mixing and chemical kinetics need to be considered when modeling the MILD regime. Furthermore, the majority of the models available require reassessing for non-conventional regimes, since they were derived for traditional flame conditions. As a result, particular attention needs to be paid to the combustion model and to the possibility of simplifying the kinetic mechanisms. 
Ghadamgahi et al. [21] employed the steady laminar flamelet model (SLFM) to solve the probability density function (PDF) for combustion to model a flameless oxy-fuel burner. There are a few more studies available in the literature about the use of Transported PDF methods to simulate MILD combustion burners. Wang et al. [22] showed that the Transported PDF (TPDF) methods successfully predict temperature and species concentrations for the Jet in a Hot Coflow burner. Lee et al. [23] employed a multi-environment PDF method to simulate the same burner to study auto-ignition, flame lift-off, and flame structure. The authors report good agreement between the numerical prediction and experimental evidence, although some discrepancies can be noticed.

Encouraging results in the literature on the modeling of MILD burners and industrial furnaces have been found using the Eddy Dissipation Concept (EDC) model by Magnussen [24-26], coupled with detailed chemical mechanisms. A review of those results may be found in Fortunato et al. [27]. Recently, Bösenhofer et al. [28] reviewed the classical formulation of the EDC and its modifications proposed in the literature, which aim at extending the validity of the EDC to MILD conditions. Another model that is able to take into account finite-rate chemistry is the Partially-Stirred Reactor (PaSR) model [29]. Zhiyi et al. [30] and Ferrarotti et al. [31] have applied this approach to MILD combustion systems with extremely good results.

The estimation of $\mathrm{NO}_{x}$ emissions in the MILD regime also requires a specific strategy. In MILD combustion, the lower temperatures and the absence of large fluctuations inhibit the NO formation through the Zeldovich thermal mechanism, which is the major formation route in most conventional combustion systems. $\mathrm{NO}_{\mathrm{x}}$ emissions in the MILD regime are mostly the result of alternative paths, such as the Fenimore's prompt $\mathrm{NO}$ [32] and/or $\mathrm{N}_{2} \mathrm{O}$ intermediate [33]. Furthermore, for hydrogen-enriched fuels, it is also necessary to consider the NNH route [34]. Those findings have been recently confirmed by Fortunato et al. [35], who investigated the behavior of two $\mathrm{H}_{2}$-enriched low calorifc value fuels in terms of $\mathrm{NO}_{x}$ emissions. The authors confirmed the importance of including all the formation routes to correctly predict the $\mathrm{NO}_{\mathrm{x}}$ emissions.

The present work focuses on the assessment of the performances of a combustion chamber for a mGT operating in the MILD regime. The behavior of the combustion chamber was evaluated mainly in terms of pollutant emissions for two fuels (methane and biogas) at various air inlet temperatures and air-to-fuel ratios. A Computational Fluid Dynamic (CFD) model was used to model the different experimental cases. Particular attention was paid to the turbulence-chemistry interaction model. Both the Eddy Dissipation Concept and the Partially Stirred Reactor were investigated to properly capture the behavior of the combustion chamber.

\section{Experimental Setup}

A combustion chamber operating in the MILD regime was designed for the large air-to-fuel ratio required by the cycle of the mGT. The combustor can burn both methane and biogas, at various inlet air temperatures and air-to-fuel ratios. This combustion chamber was designed specifically for an inverted Brayton cycle mGT, using CFD-tools. More details about the mGT can be found in Delanaye et al. [36]. The design methodology and its results are reported by Fortunato et al. [37]. The combustion chamber is a horizontal cylinder, with a diameter of $0.042 \mathrm{~m}$; the reactants are fed by means of a central fuel jet, surrounded by an annular inlet for primary air. A different gas injector is used for the ignition process. The MILD regime is achieved by switching to the main gas injector as soon as the chamber is heated up. The recirculation of the exhaust gases required to establish the MILD regime is possible because of the geometry of the chamber and the design of the gas inlet nozzles. The strong recirculation leads to a reduction of the oxygen concentration of the air inlet which allows it to reach the MILD regime conditions.

The combustion chamber was thoroughly modeled with advanced CFD analysis, prior to the manufacturing of the prototype. The Navier-Stokes equations were solved on an axisymmetric domain. The two-equations $k-\varepsilon$ model [38] was employed to model turbulence; turbulence-chemistry interactions were taken into account using the EDC model [24] and the gas-phase oxidation was 
modeled with a detailed kinetic mechanism, namely the GRI 2.11 [39]. The air was preheated up to $730{ }^{\circ} \mathrm{C}$ before entering the combustion chamber. Figure 1 shows the velocity distribution inside the combustion chamber. A major recirculation zone is noticeable in the chamber. From the profiles of temperature along the axis, together with the radical $\mathrm{OH}$ mass fraction, as shown in Figure 2, it can be noticed that there is a very limited increase with respect to the inlet temperature and no peaks of temperature are visible. Furthermore, the location of the peak of radical $\mathrm{OH}$ concentration shows that the reaction zone is located toward the end of the chamber and the main recirculation zone, as visible comparing Figures 1 and 2. This further proves that the combustion happens in the MILD regime: the reaction occurs in diluted conditions and not when the reactants first mix. The combustion efficiency is estimated to be higher than $99.5 \%$ and no noticeable $\mathrm{CO}$ and $\mathrm{NO}_{\mathrm{x}}$ concentration were detected.

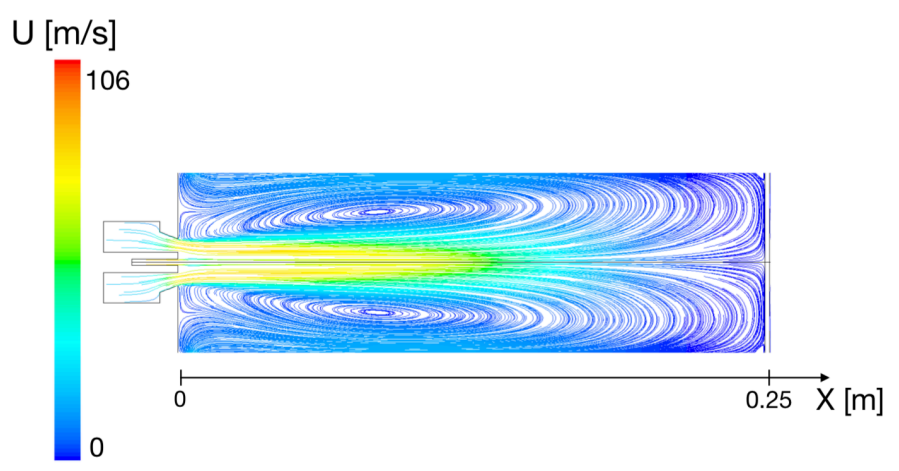

Figure 1. Velocity distribution $(\mathrm{m} / \mathrm{s})$ inside the combustion chamber. EDC-GRI2.11 numerical model.

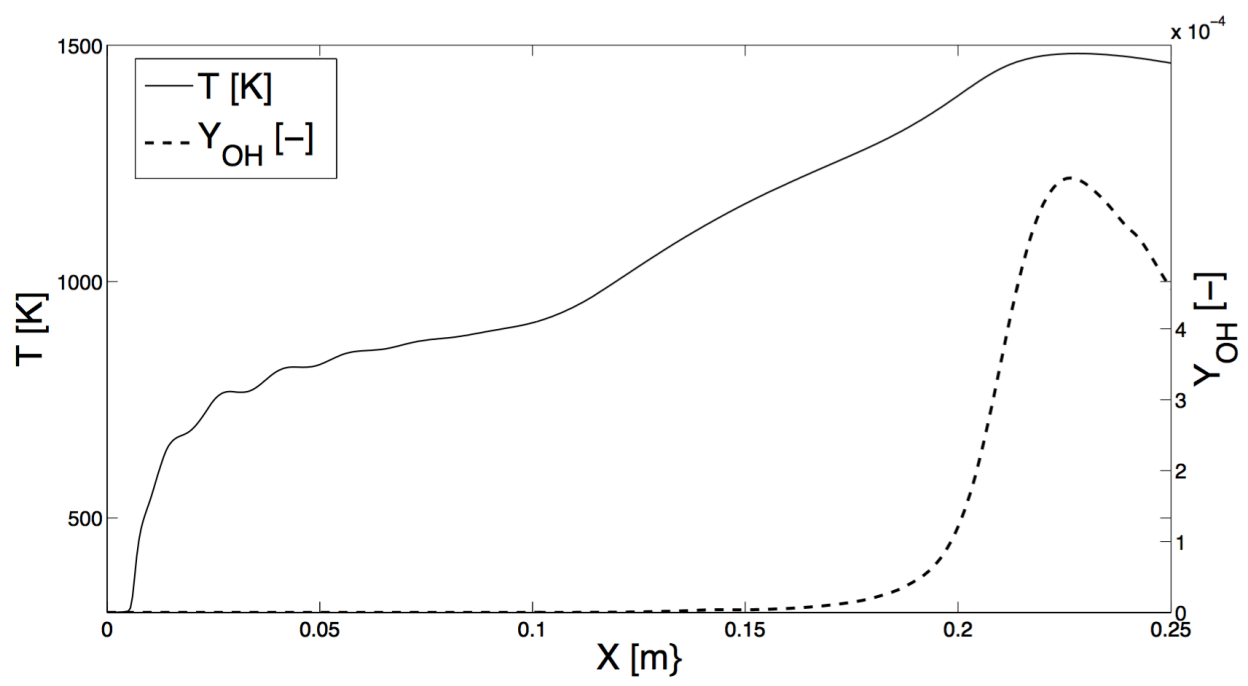

Figure 2. Temperature distribution $(\mathrm{K})$ and radical $\mathrm{OH}$ mass fraction (-) along the axis of the combustion chamber. EDC-GRI2.11 numerical model.

The prototype of this combustion chamber is realised and installed in the laboratories of MITIS SA, in Liège, Belgium. The combustion chamber is made of AISI 310S. All the installation is covered with insulating material, to prevent heat loss. The thermal input, defined as the product of the mass flow rate of fuel and its lower heating value, is $4.75 \mathrm{~kW}$. The main issue prior to the test of the combustion chamber was the preheating of the inlet air. Following the CFD calculations, air needs to enter the combustion chamber at around $730{ }^{\circ} \mathrm{C}$. In this experimental set-up (shown schematically in Figure 3), this problem was solved using an electrical preheater. The air volumetric flow was measured with a Von Karman Vortex flow meter. Two thermocouples (type K) measured the temperature of the air at the inlet of the chamber (outlet of the preheater) and the temperature at the outlet of the 
combustion chamber. NI DAQ and LabView2016 software, provided by National Instruments, were used to monitor all the instruments described. A portable gas analyzer (TESTO 350) was used to measure the concentration on dry basis in the flue gas of $\mathrm{O}_{2}$ (percentage in volume), $\mathrm{CO}_{2}$ (percentage in volume), $\mathrm{CO}$ (ppm), and $\mathrm{NO}_{\mathrm{x}}(\mathrm{ppm})$. Measurements were taken at the exit of the combustion chamber. The range and resolution for the sensors of the gas analyzer can be found in Table 1 .

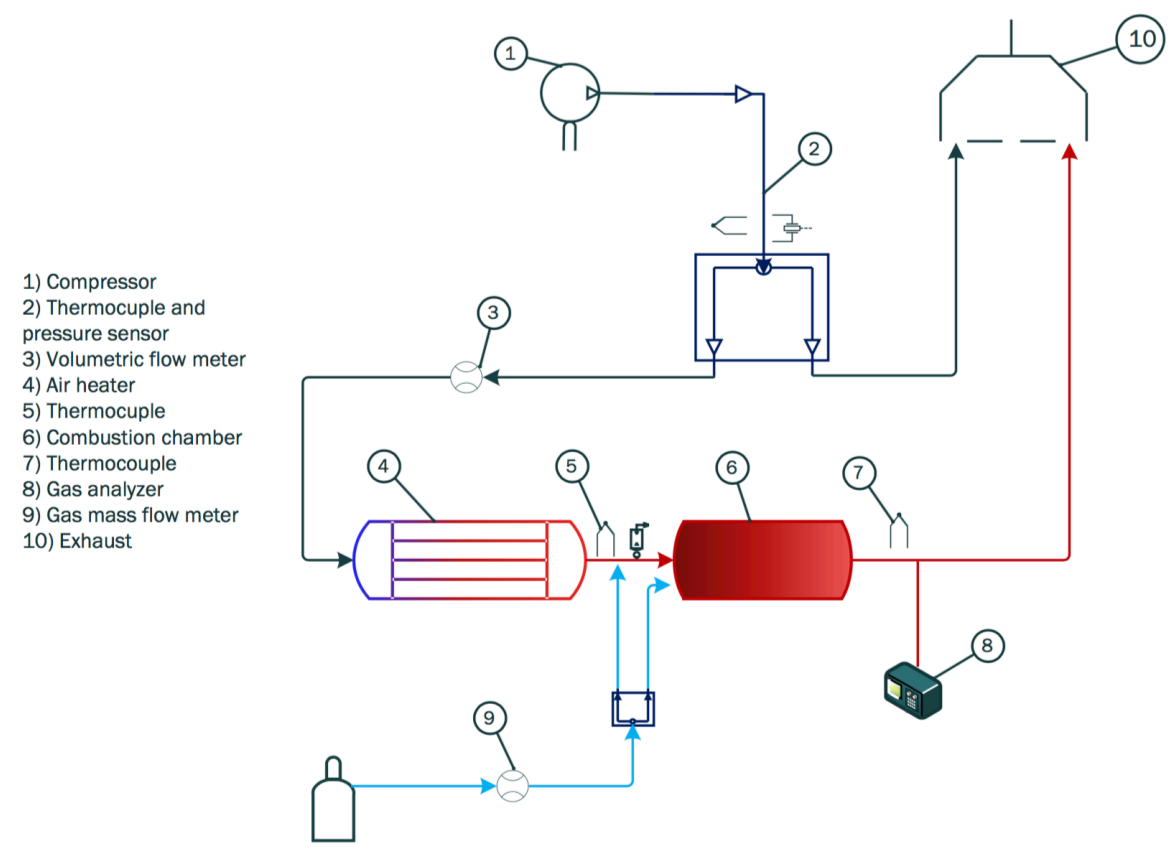

Figure 3. Schematic representation of the test-bench.

Table 1. Gas analyzer sensor range and resolution.

\begin{tabular}{ccc}
\hline Sensor & Range & Resolution \\
\hline $\mathrm{CO}$ & $0-10,000 \mathrm{ppm}$ & $1 \mathrm{ppm}$ \\
$\mathrm{NO}$ & $0-4000 \mathrm{ppm}$ & $3 \mathrm{ppm}$ \\
$\mathrm{CH}_{4}$ & $100-40,000 \mathrm{ppm}$ & $10 \mathrm{ppm}$ \\
$\mathrm{CO}_{2}$ & $0-50 \%$ vol & $0.01 \%$ vol \\
$\mathrm{O}_{2}$ & $0-25 \%$ vol & $0.01 \%$ vol \\
\hline
\end{tabular}

\section{Experimental Results}

The experiments were carried out with the goal of assessing the effect of the air inlet temperature and the air-to-fuel ratio, $\lambda$, on the pollutant emissions. The different $\lambda$ values were obtained by keeping the fuel flow constant and changing the air flow. Two different fuels were analyzed: methane and biogas. Table 2 summarizes the conditions for all the experimental runs for both fuels.

The results for methane are presented first, followed by those for biogas.

\subsection{Methane}

As mentioned before, the parameters under investigation were the air inlet temperature and the air-to-fuel ratio, $\lambda$. The nominal values for those two parameters, obtained from the CFD calculations, are $730{ }^{\circ} \mathrm{C}$ and 3.5, respectively. For this experiment, the measurements of the outlet temperature were not taken because of a malfunctioning thermocouple. 
Table 2. Summary of the conditions for all the experimental runs, for both methane and biogas.

\begin{tabular}{ccc}
\hline \multicolumn{3}{c}{ Methane } \\
\hline Run & Air-to-Fuel ratio (-) & Air Inlet Temperature $\mathbf{(}^{\circ}$ ) \\
\hline 1 & 1.5 & 330 \\
2 & 1.5 & 430 \\
3 & 1.5 & 530 \\
4 & 1.5 & 630 \\
5 & 1.5 & 730 \\
6 & 2.5 & 530 \\
7 & 2.5 & 630 \\
8 & 2.5 & 730 \\
9 & 3.5 & 530 \\
10 & 3.5 & 630 \\
11 & 3.5 & 730 \\
12 & 4.5 & 730 \\
\hline & & \\
\hline & Biogas & \\
\hline 1 & Air-to-Fuel ratio (-) & Air Inlet Temperature $\left(^{\circ}\right)$ \\
\hline 2 & 1.67 & 500 \\
3 & 1.67 & 600 \\
4 & 1.67 & 700 \\
5 & 2.33 & 500 \\
6 & 2.33 & 700 \\
7 & 2.33 & 500 \\
8 & 2.55 & 700 \\
9 & 2.55 &
\end{tabular}

Figure 4 shows the $\mathrm{O}_{2}$ concentration in the exhaust gases as a function of the air-to-fuel ratio for different values of the air inlet temperature. The error bars represent the standard deviation on each measurement, calculated on all the points collected for a single run. Moreover, the same operating conditions were duplicated several times to verify the repeatability of the test. It is possible to notice that the $\mathrm{O}_{2}$ concentration was not affected by the air inlet temperature.

Figure 5 and 6 report the concentration of $\mathrm{CO}$ and $\mathrm{NO}_{x}$ emissions at the outlet of the chamber. The values are normalized for an $\mathrm{O}_{2}$ concentration of $15 \%$ in the exhausts. This is necessary to better compare the results obtained at very different air excess values, and therefore, very different oxygen levels in the exhaust gases. The value of $15 \%$ was chosen following the terms of the environmental regulations for gas turbines in Europe. For CO emissions for example, the normalization is the result of the following formula:

$$
C O_{\text {norm }}=\mathrm{CO}_{\text {meas }} \frac{\mathrm{O}_{2, \text { air }}-\mathrm{O}_{2, \text { ref }}}{\mathrm{O}_{2, \text { air }}-\mathrm{O}_{2, \text { meas }}}
$$

where $\mathrm{CO}_{\text {meas }}$ is the concentration of $\mathrm{CO}$ measured in the exhaust gases, $\mathrm{O}_{2, \text { ref }}$ is the concentration of $\mathrm{O}_{2}$ chosen for the normalization ( $15 \%$ volume in this case), $\mathrm{O}_{2, \text { meas }}$ is the concentration of $\mathrm{O}_{2}$ measured in the exhaust gases, and $\mathrm{O}_{2, \text { air }}$ is the concentration of $\mathrm{O}_{2}$ in the air. In this case, all the concentrations are volumetric.

The $\mathrm{CO}$ emissions were close to $0 \mathrm{ppm}$ for all the conditions, showing that the combustion process was complete. For the case $T_{\text {in }}=730^{\circ} \mathrm{C}$ and $\lambda=4.5, \mathrm{CO}$ emissions were $3 \mathrm{ppm}$ and $0 \mathrm{ppm}$ for the other cases. The difference can be explained by the fact that there is a statistical error of $\pm 1 \mathrm{ppm}$ and $\pm 3 \mathrm{ppm}$ that comes from the accuracy of the instrument. The values of the $\mathrm{NO}_{\mathrm{x}}$ emissions were very low for most of the runs, even in the presence of a high level of air preheating. Higher emissions can be noticed for the run at $\lambda=1.5$. 

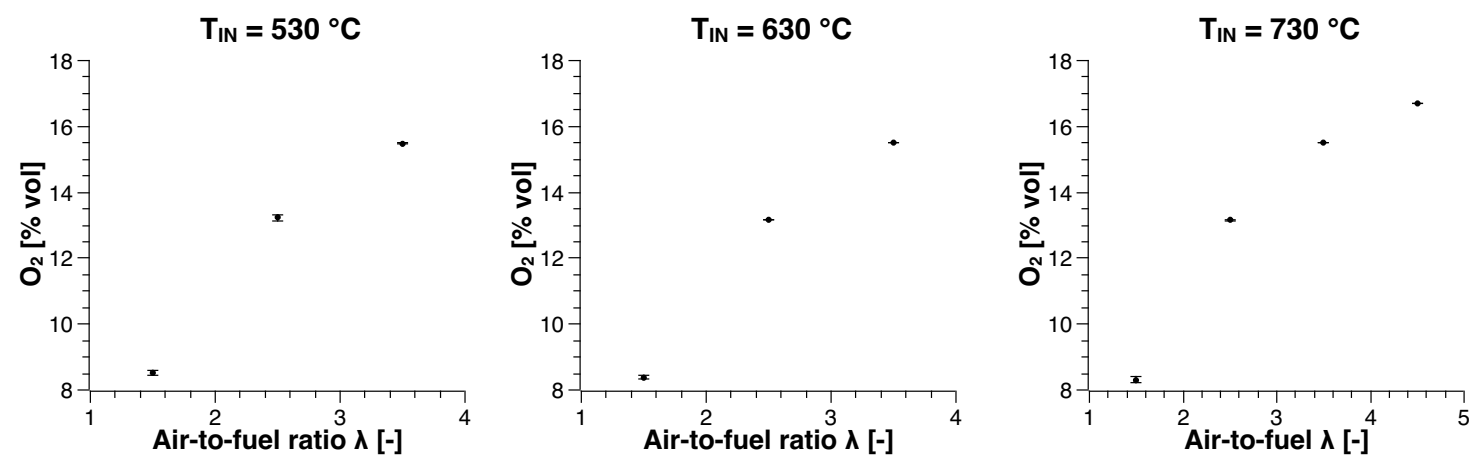

Figure 4. $\mathrm{O}_{2}$ concentration ( $\left.\% \mathrm{vol}\right)$ in the exhaust gases as a function of the air-to-fuel ratio $\lambda$ for different values of the air inlet temperature.

$\mathrm{T}_{\mathrm{IN}}=530^{\circ} \mathrm{C}$

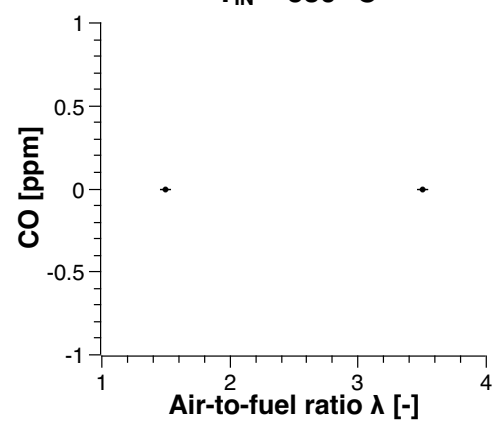

$\mathrm{T}_{\mathrm{IN}}=630^{\circ} \mathrm{C}$

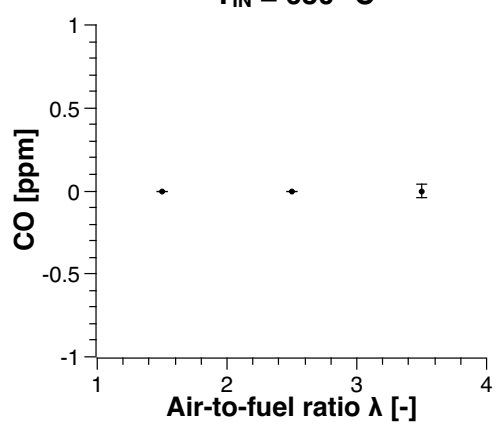

$\mathrm{T}_{\mathrm{IN}}=730^{\circ} \mathrm{C}$

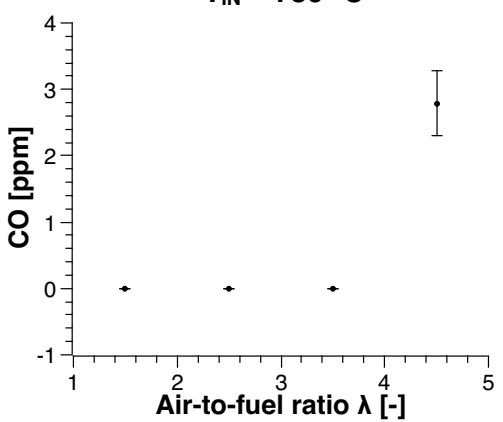

Figure 5. $\mathrm{CO}$ concentration (ppm) in the exhaust gases, normalized at $15 \% \mathrm{O}_{2}$, as a function of the air-to-fuel ratio $\lambda$ for different values of the air inlet temperature.
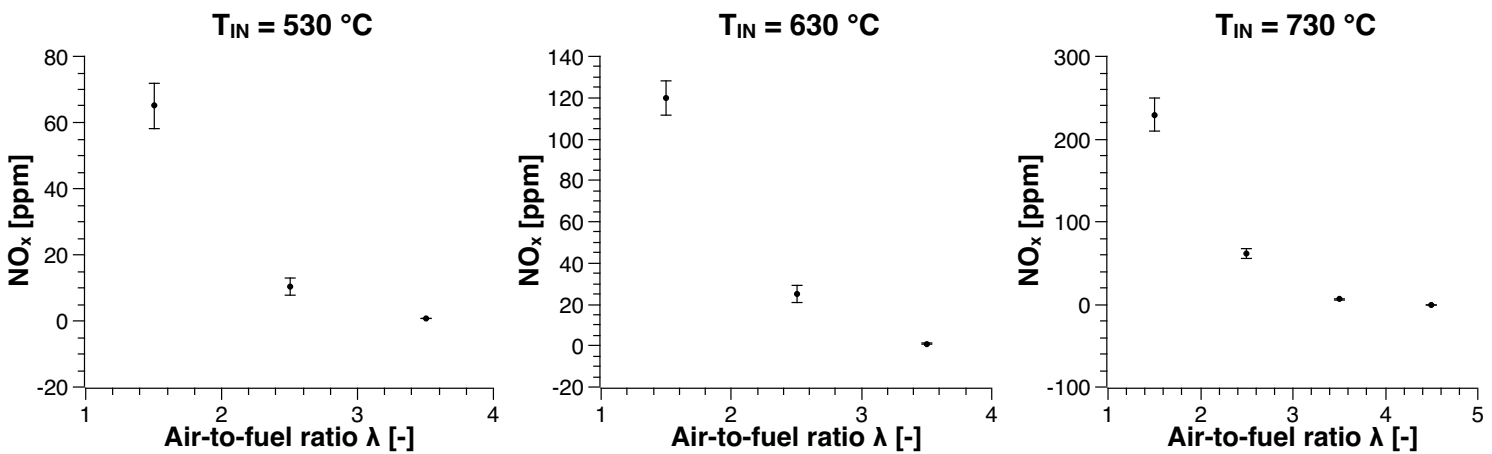

Figure 6. $\mathrm{NO}_{\mathrm{x}}$ concentration (ppm) in the exhaust gases, normalized at $15 \% \mathrm{O}_{2}$, as a function of the air-to-fuel ratio $\lambda$ for different values of the air inlet temperature.

To better understand the effect of this parameter, tests were also run for different values of the air-to-fuel ratio $\lambda$. Figure 7 shows the $\mathrm{O}_{2}$ concentration in the exhaust gases for three different values of $\lambda$ as a function of the air inlet temperature. It is possible to notice that for higher values of $\lambda$, it was not possible to sustain the combustion process for the lowest values of the air inlet temperature, namely $330{ }^{\circ} \mathrm{C}$ and $430{ }^{\circ} \mathrm{C}$. Moreover, it was confirmed that the air inlet temperature did not affect the $\mathrm{O}_{2}$ concentration in the exhaust. $\mathrm{CO}$ emissions for three different values of $\lambda$ as a function of the air inlet temperature are reported in Figure 8. The values are close to $0 \mathrm{ppm}$ for all the runs, which indicates a complete combustion process. The exception is the condition $\lambda=1.5$ and $T=330^{\circ}$; for this point, the limited air excess and the lower inlet temperature did not provide optimal conditions to achieve complete combustion. Finally, Figure 9 shows the $\mathrm{NO}_{\mathrm{x}}$ emissions for the different cases under investigation. The best results were obtained for the runs $\lambda=3.5$, which is the nominal value. In this case, for all the values of air inlet temperature, $\mathrm{NO}_{\mathrm{x}}$ emissions were below $7 \mathrm{ppm}$. For the runs 
$\lambda=1.5, \mathrm{NO}_{\mathrm{x}}$ emissions rapidly increased with the air inlet temperature. This is due to the fact that higher temperatures were reached inside the chamber because of the lower air excess. For the same reason, the runs $\lambda=2.5$ were characterized by $\mathrm{NO}_{\mathrm{x}}$ emissions higher than the case $\lambda=3.5$.
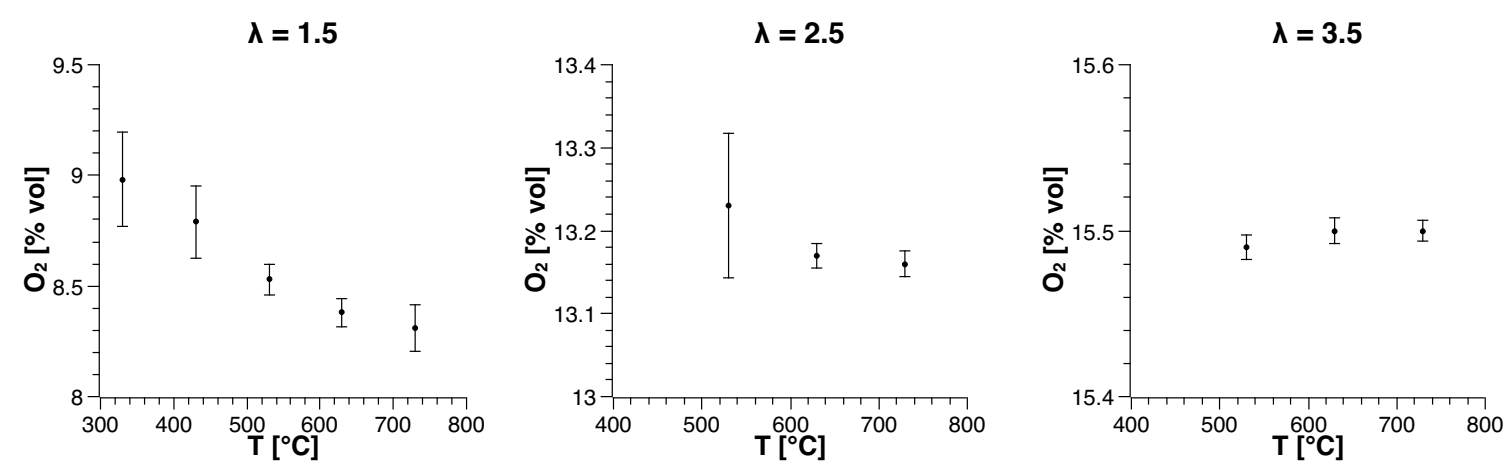

Figure 7. $\mathrm{O}_{2}$ concentration $(\% \mathrm{vol})$ in the exhaust gases as a function of the air inlet temperature for different values of the air-to-fuel ratio $\lambda$.
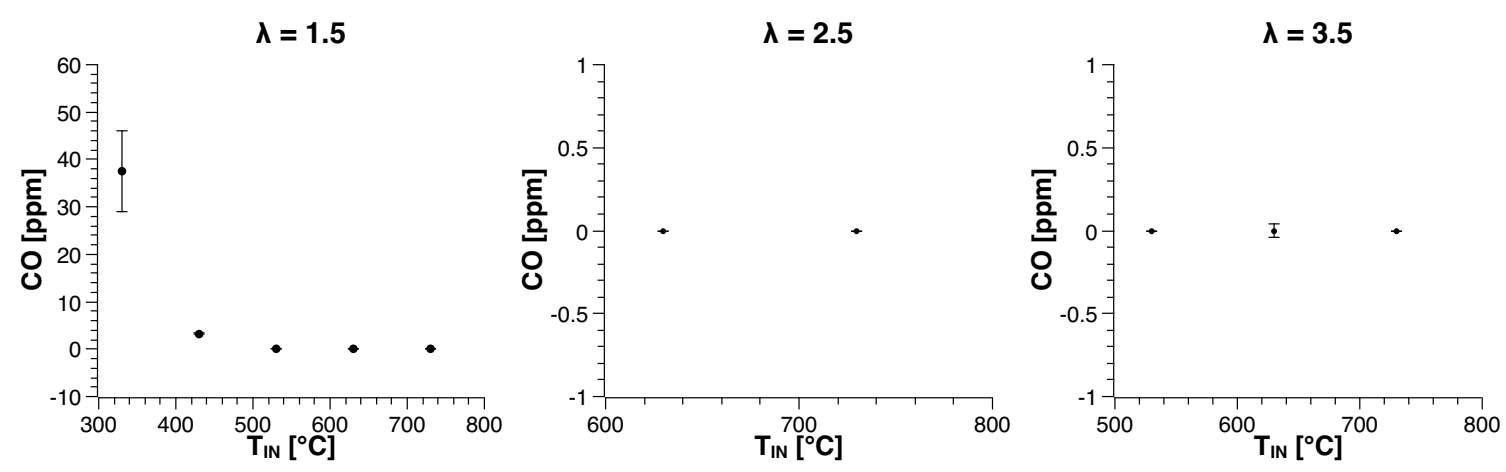

Figure 8. CO concentration (ppm) in the exhaust gases, normalized at $15 \% \mathrm{O}_{2}$, as a function of the air inlet temperature for different values of the air-to-fuel ratio $\lambda$.

$\Lambda=1.5$

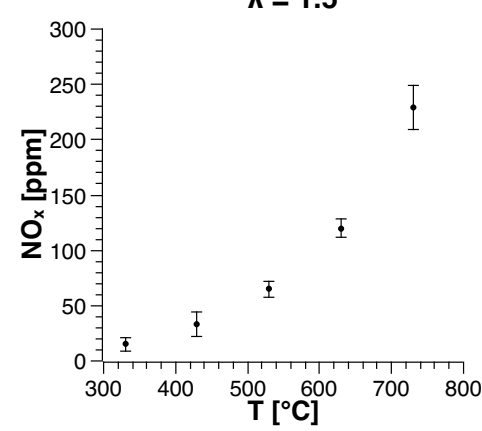

$\lambda=2.5$

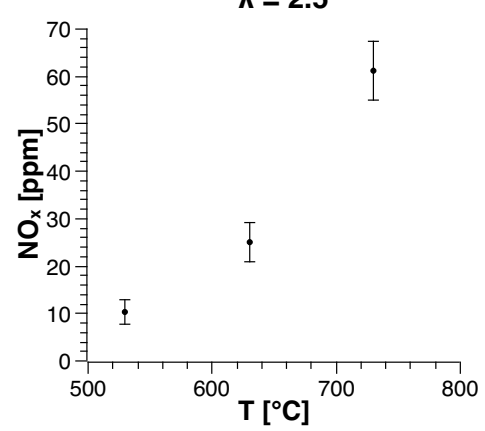

$\lambda=3.5$

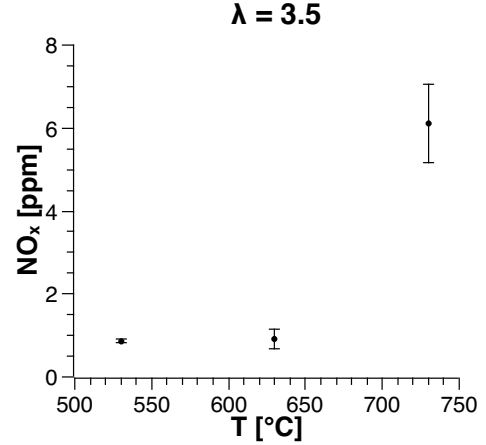

Figure 9. $\mathrm{NO}_{\mathrm{x}}$ concentration (ppm) in the exhaust gases, normalized at $15 \% \mathrm{O}_{2}$, as a function of the air inlet temperature for different values of the air-to-fuel ratio $\lambda$.

The data presented show that the combustion chamber behaves well in terms of polluttant emissions and its performances are stable over a large range of inlet conditions.

\subsection{Biogas}

As discussed in Section 1, one of the main advantages of the MILD combustion regime is its fuel flexibility. Indeed, the combustion chamber under investigation is able to burn biogas as well as methane. The term biogas usually refers to a mixture of different gases produced by the anaerobic 
digestion of organic matter. It is mainly composed of methane and carbon dioxide, with possible traces of hydrogen, carbon monoxide, nitrogen, and hydrogen sulfide. The composition of the biogas investigated in the present work is reported in Table 3. Its lower heating value is $21 \mathrm{MJ} / \mathrm{kg}$, less than half that of methane $(50 \mathrm{MJ} / \mathrm{kg})$.

Table 3. Composition (\% vol) of the biogas.

\begin{tabular}{cccc}
\hline $\mathbf{C H}_{\mathbf{4}}$ & $\mathbf{H}_{\mathbf{2}}$ & $\mathrm{CO}_{\mathbf{2}}$ & $\mathbf{N}_{\mathbf{2}}$ \\
\hline 66 & 0.8 & 31 & 2.2 \\
\hline
\end{tabular}

The test bench as well as the equipment employed were the same used for the tests with methane. In particular, the same gas flow meter was used, which led to an error in the evaluation of the gas flow. Indeed, the tests had been designed for an air-fuel equivalence ratio $\lambda=3.5$, calculated based on a biogas mass flow able to ensure the same thermal input power as that of pure methane. However, because of a calibration error on the gas flow meter, tests were run for values of $\lambda$ lower than the nominal one. The exact values were calculated a posteriori, from the $\mathrm{O}_{2}$ concentration in the exhaust gases. The tests were run for three values of $\lambda(2.55,2.33$, and 1.67) and three different air inlet temperatures $\left(500,600\right.$, and $700{ }^{\circ} \mathrm{C}$ ). During the tests with $\lambda=1.67$, the high temperature, generated because of the proximity to stoichiometric conditions, damaged the combustion chamber, and therefore, it was not possible to perform further tests with biogas.

The combustion chamber also performed well when biogas was employed, even though the conditions investigated are quite far from the design point $(\lambda=3.5)$. The outlet temperature for the three levels of air preheating is shown in Figure 10. For each point, the error bar represents the standard deviation calculated on all the points collected for a single run. It is possible to notice that the temperature increased when $\lambda$ decreased, as expected, because of the lower air excess in the system. Larger standard deviations are associated with the results of the runs at $500{ }^{\circ} \mathrm{C}$ and especially for the one $\lambda=1.67$. Those were the last tests performed before the chamber broke down. Therefore, the uncertainty on those results may be due to the instabilities observed during the operation, originating from the damages to the chamber.

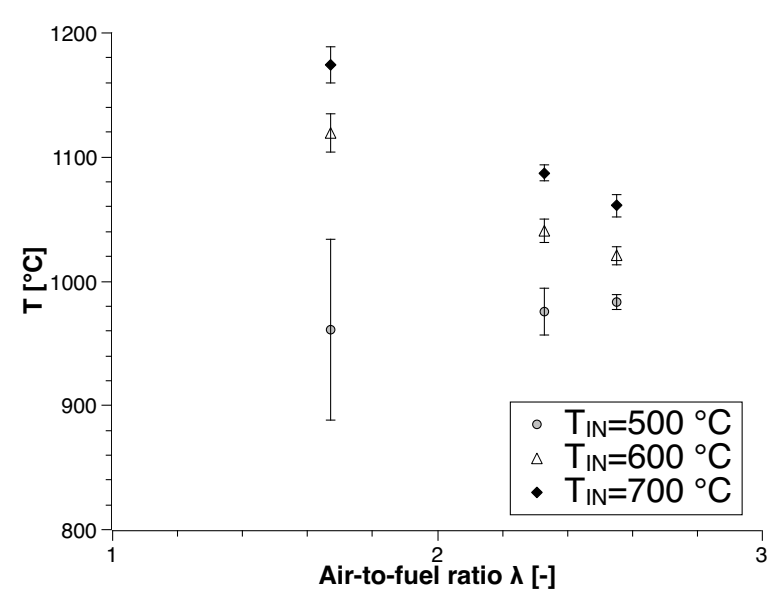

Figure 10. Exhaust gases temperature $\left({ }^{\circ} \mathrm{C}\right)$ for different values of air-fuel equivalence ratios and different air inlet temperatures.

The concentrations of $\mathrm{O}_{2}, \mathrm{CO}$, and $\mathrm{NO}_{\mathrm{x}}$ in the exhaust gases for the three different air inlet temperatures are reported in Figures 11-13. In this case as well, the $\mathrm{CO}$ and $\mathrm{NO}_{\mathrm{x}}$ values are corrected to $15 \%$ of oxygen in the exhausts. 

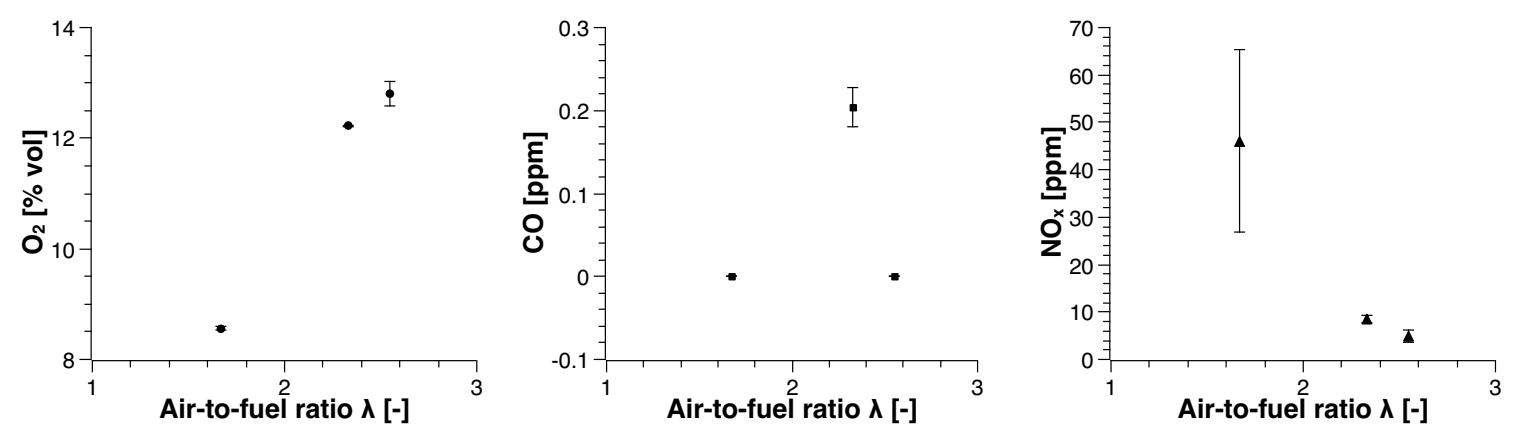

Figure 11. Concentrations of $\mathrm{O}_{2}(\% \mathrm{vol}), \mathrm{CO}(\mathrm{ppm})$, and $\mathrm{NO}_{\mathrm{x}}(\mathrm{ppm})$ as a function of air-to-fuel ratio $\lambda$. Air inlet temperature $500{ }^{\circ} \mathrm{C}$.
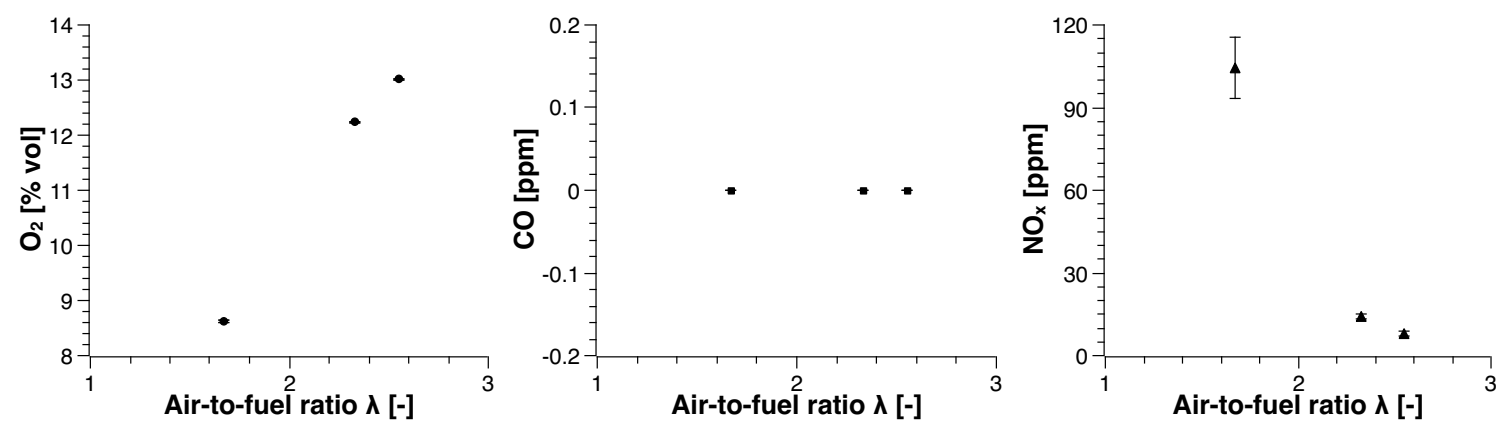

Figure 12. Concentrations of $\mathrm{O}_{2}(\% \mathrm{vol}), \mathrm{CO}(\mathrm{ppm})$, and $\mathrm{NO}_{\mathrm{x}}(\mathrm{ppm})$ as a function of air-to-fuel ratio $\lambda$. Air inlet temperature $600{ }^{\circ} \mathrm{C}$.
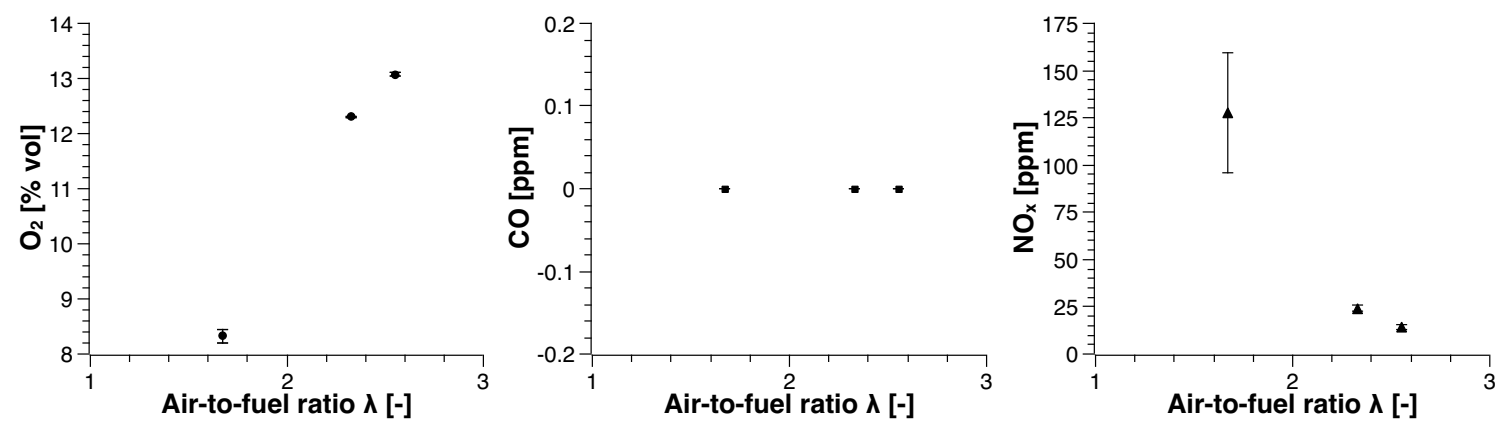

Figure 13. Concentrations of $\mathrm{O}_{2}(\% \mathrm{vol}), \mathrm{CO}(\mathrm{ppm})$, and $\mathrm{NO}_{\mathrm{x}}(\mathrm{ppm})$ as a function of air-to-fuel ratio $\lambda$. Air inlet temperature $700^{\circ} \mathrm{C}$.

As expected, $\mathrm{O}_{2}$ concentration in the exhaust gases increased when $\lambda$ increased. The $\mathrm{CO}$ emissions were close to $0 \mathrm{ppm}$ for all the runs, indicating that the combustion process was complete. The $\mathrm{NO}_{\mathrm{x}}$ emissions were relatively high for a MILD system, but this can be explained with the higher temperatures due to the lower air excess in the combustion chamber. Moreover, based on the damages reported, it is possible that some hot spots originated inside the chamber for the lower $\lambda$ values. Satisfactory values were obtained for $\lambda=2.55$, for which the $\mathrm{NO}_{\mathrm{x}}$ were 5,8 , and $14 \mathrm{ppm}$ for an air inlet temperature of 500,600 , and $700{ }^{\circ} \mathrm{C}$, respectively. The emissions increased slightly for $\lambda=2.33(9,14$, and $24 \mathrm{ppm}$ for an air inlet temperature of 500,600 , and $700{ }^{\circ} \mathrm{C}$, respectively), because of the lower air excess and the consequently higher temperatures. Finally, for $\lambda=1.67$, the $\mathrm{NO}_{\mathrm{x}}$ concentrations were quite elevated. Indeed, they went from $46 \mathrm{ppm}$ for the air inlet temperature $500{ }^{\circ} \mathrm{C}$ to $104 \mathrm{ppm}$ and $127 \mathrm{ppm}$ for air inlet temperatures $600{ }^{\circ} \mathrm{C}$ and $700{ }^{\circ} \mathrm{C}$, respectively. All values are normalized 
for $15 \%$ of $\mathrm{O}_{2}$ in the exhausts. It is worth reminding that $\lambda=1.67$ is extremely far from the nominal operating condition.

Despite the relatively high values of $\mathrm{NO}_{\mathrm{x}}$ emissions discussed above, the combustion chamber proved to be fuel flexible. Both ignition and stable combustion could be achieved when biogas was burnt.

\section{Numerical Study}

The availability of data collected during the experiments allows the validation of the numerical model employed to design the chamber. The numerical calculations were done with the commercial software Ansys Fluent 17.0. The computational grid consisted of $114 \mathrm{k}$ cells and it is the result of a mesh independency study. The domain was 2D axisymmetric. For sake of clarity, the mesh is plotted in Figure 14. More details can be found in Fortunato et al. [37] and Delanaye et al. [36]. Turbulence was modeled with the Modified $k-\varepsilon$ model proposed by Morse [40], which consists in the variation of the first constant of the turbulent kinetic energy dissipation equation from 1.44 to 1.6. It has been proved that this modification leads to better predictions of the spread of the round jets [27]. To take into account the turbulence-chemistry interactions, the Eddy Dissipation Concept (EDC) [24] and the Partially Stirred Reactor (PaSR) [29] models were used. To reduce the computational costs, both combustion models were coupled with the In Situ Adaptive Table (ISAT) [41]. An error tolerance of $10^{-5}$ was selected to obtain table-independent results. Several kinetic schemes were evaluated:

- KEE58 [42]; it consists of 17 species and 58 reversible chemical reactions.

- GRI 3.0 [43]; it is implemented without the $\mathrm{NO}_{x}$ reactions, resulting in 35 species and 217 reactions.

- POLIMI, a skeletal mechanism reduced ad hoc for the conditions of this combustion chamber. The reduction technique is based on a species-targeted sensitivity analysis, as explained by Stagni et al. [44]; it is obtained starting from the detailed mechanism POLIMI [45]. For methane, it consists of 25 species and 154 reactions, whereas for biogas 25 species and 170 reactions are needed.

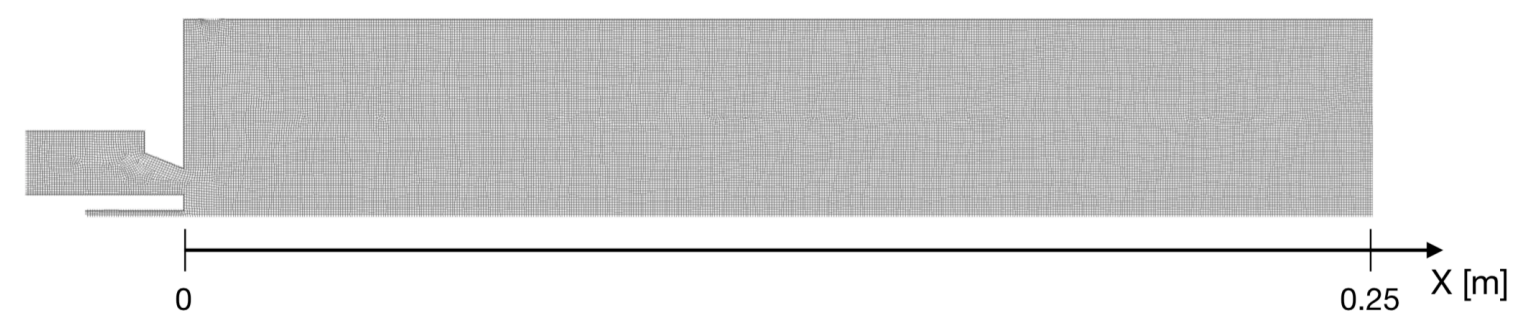

Figure 14. Computational grid for the $2 \mathrm{D}$ axisymmetric domain of the combustion chamber.

The $\mathrm{NO}_{\mathrm{x}}$ emissions were estimated taking into account several formation paths: thermal $\mathrm{NO}$, Fenimore's Prompt route, and via $\mathrm{N}_{2} \mathrm{O}$ path. The Thermal NO route consists in a simplified one-step reaction with a Finite Rate combustion model, derived from the Zeldovich full mechanism by assuming a steady state for the $\mathrm{N}$ radicals and calculating the $\mathrm{O}$ radical from the dissociation reaction of the oxygen [46]. The Prompt NO route is included according to De Soete [47] while the via $\mathrm{N}_{2} \mathrm{O}$ path is taken into account following Malte and Pratt [33]. The NNH route is implemented by means of a User Defined Function (UDF) as suggested by Konnov [34]. All the kinetic rates are integrated over a probability density function (PDF) for temperature to include the effect of temperature fluctuations on the mean reaction rates. The assumed PDF shape is that of a beta function [48] and is calculated with a transport equation for the temperature variance. All the equations are dicretized with a second-order upwind scheme and the SIMPLE algorithm was adopted for pressure-velocity coupling. The solutions were considered converged when the residuals for all the resolved quantities decreased by at least six 
orders of magnitude. Moreover, flow field variables at different locations were monitored to assure that the steady state was reached.

\subsection{Methane}

At first, the Eddy Dissipation Concept was considered to model the combustion chamber. The comparison between measured and computed values of different species concentrations in the exhaust gases, for different air-to-fuel ratio values, is shown in Figure 15. The model quite accurately predicts the concentrations of $\mathrm{O}_{2}$ and $\mathrm{CO}_{2}$ for all the four cases analyzed. The $\mathrm{CO}_{2}$ measurements are highly correlated to the outlet temperature. Figure 15 shows that the prediction for $\mathrm{CO}_{2}$ are in good agreement with the experimental data, proving that the temperature is also accurately predicted. However, it is possible to notice a discrepancy in the prediction of the CO. Aminian et al. [49] showed that CO formation is highly influenced by temperature fluctuations, which the RANS/EDC modeling strategy might fail to predict correctly. Indeed, this approach might locally lead to the overestimation of the fluctuations of the temperature, predicting higher levels of $\mathrm{CO}$ than in the real systems. The discrepancy may also be due to the kinetic mechanism which was derived for higher temperatures than the ones reached in this combustion chamber. Indeed, the maximum temperatures inside the combustion chamber, calculated through CFD, were much lower than the ones typical of traditional combustion, as shown in the temperature maps in Figure 16. In the case $\lambda=1.5$, a peak of temperature is visible in the chamber as a result of the proximity to stoichiometric conditions. This explains the high value of $\mathrm{NO}_{x}$ emissions (485 ppm) registered for this operating condition, which is nonetheless extremely far from the design operating condition. For all the other cases, the temperature field was quite homogeneous, with no peaks of temperature. Moreover, the maximum values reached were extremely low, especially for the runs $\lambda=3.5$ and $\lambda=4.5$. For those cases, the maximum temperature was well below $1700 \mathrm{~K}$.
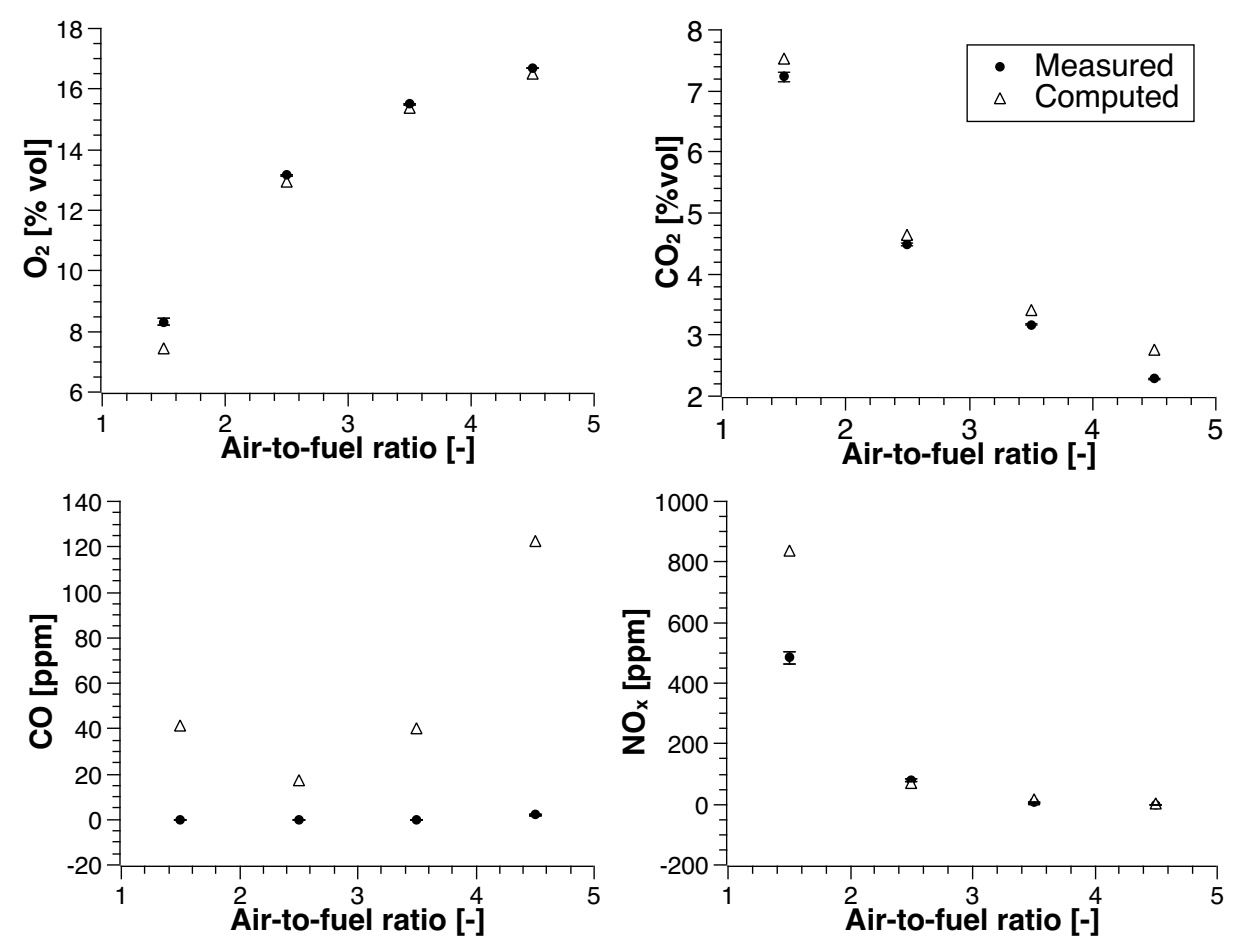

Figure 15. Comparison between measured and computed values of $\mathrm{O}_{2}(\% \mathrm{vol}), \mathrm{CO}_{2}(\% \mathrm{vol}), \mathrm{CO}(\mathrm{ppm})$, and $\mathrm{NO}_{\mathrm{x}}(\mathrm{ppm})$ concentrations in the exhaust gas for different values of the air-to-fuel ratio. Air inlet temperature $730^{\circ} \mathrm{C}$. GRI3.0 kinetic mechanism. 
As far as the $\mathrm{NO}_{\mathrm{x}}$ is concerned, the numerical model overestimated their value, especially for the case $\lambda=1.5$. Moreover, in this case , the major contribution to the $\mathrm{NO}_{\mathrm{x}}$ formation was given by the thermal pathway. In all the other cases, because of the lower temperatures, the mechanism which contributed the most to the $\mathrm{NO}_{x}$ formation was the $\mathrm{N}_{2} \mathrm{O}$ path which was responsible for $58 \%, 91 \%$, and $97 \%$ for $\lambda=2.5, \lambda=3.5$, and $\lambda=4.5$, respectively.

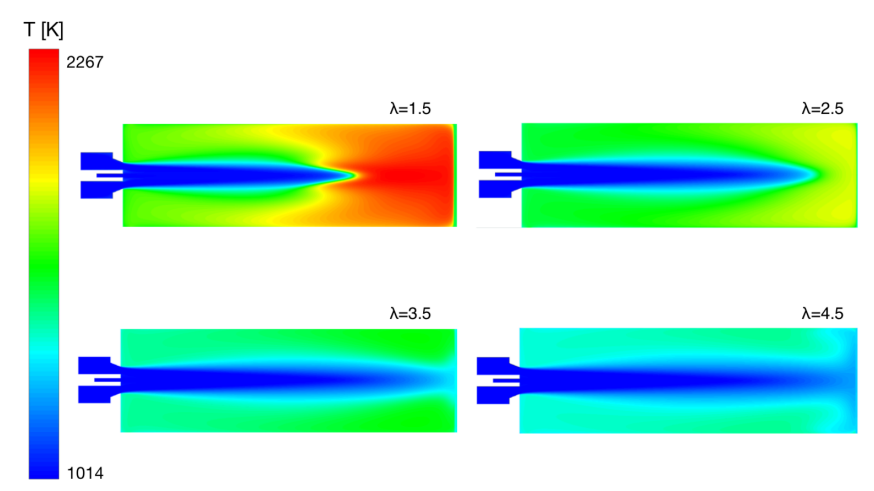

Figure 16. Temperature distribution $(\mathrm{K})$ inside the combustion chamber, for different values of the air-to-fuel ratio. Air inlet temperature $730^{\circ} \mathrm{C}$. EDC model, GRI 2.11 kinetic mechanism.

Despite the good agreement of the numerical model with the experimental evidence, the EDC approach failed to model some of the cases tested experimentally. Specifically, the EDC predicted extinction for the cases characterized by a lower air inlet temperature and therefore lower reactivity. Those cases were successfully modeled considering the Partially Stirred Reactor (PaSR) as the combustion model. A key issue with this model is the correct estimation of the mixing and chemical timescales. The mixing timescale is proportional to the ratio of the turbulent kinetic energy and its dissipation. The proportionality constant, called hereafter $C_{\text {mix }}$, is user-dependent and it can vary between 0.001 and 1 . The chemical timescale is affected by the choice of chemical species to describe the gas-phase oxidation. Therefore, different kinetic mechanisms lead to different results.

First, the effect of different values of the constant $C_{m i x}$ was evaluated. Figure 17 shows the comparison between the measured values of different species concentrations in the exhaust gases and the values predicted with four different $C_{m i x}$ for the three air inlet temperature analyzed. The air-to-fuel ratio was $\lambda=3.5$ and the kinetic mechanism in this first evaluation was the KEE58. It is possible to notice that the model with $\mathrm{C}_{m i x}=0.5$ predicted extinction for the cases without a sufficiently high inlet temperature (same behavior of EDC). The best results were obtained with $\mathrm{C}_{m i x}=0.1$, especially for the $\mathrm{CO}$ emissions. This value was used in the following evaluation of the kinetic mechanism.

As mentioned before, the chemical timescale was somewhat affected by the choice of the species that describe the gas-phase oxidation. Therefore, three different kinetic schemes were tested: the KEE58, the GRI3.0 and a skeletal mechanism reduced ad-hoc from POLIMI full mechanism. Figure 18 shows the comparisons between the prediction of the PaSR model coupled with the different kinetic mechanisms and the measured values of different species concentrations in the exhaust gases, for the three air inlet temperature analyzed. The air-to-fuel ratio was $\lambda=3.5$. It is possible to notice that the GRI3.0 provided the best results. In particular, the $\mathrm{CO}$ emissions were captured much more accurately when compared to the other mechanisms. Finally, the performances of the EDC and the PaSR were compared for the air inlet temperature $730^{\circ} \mathrm{C}$, for different values of the air-to-fuel ratio. The results are shown in Figure 19. The PaSR performed better than the EDC, especially for CO emissions. As explained before, the EDC usually overestimated the CO emissions. On the other hand, the PaSR model better captures the finite-rate chemistry that characterizes the MILD combustion regime. Therefore, the $\mathrm{CO}$ emissions are much better predicted. Furthermore, as already stated before, the EDC failed to model the cases with lower inlet temperature and lower reactivity. 

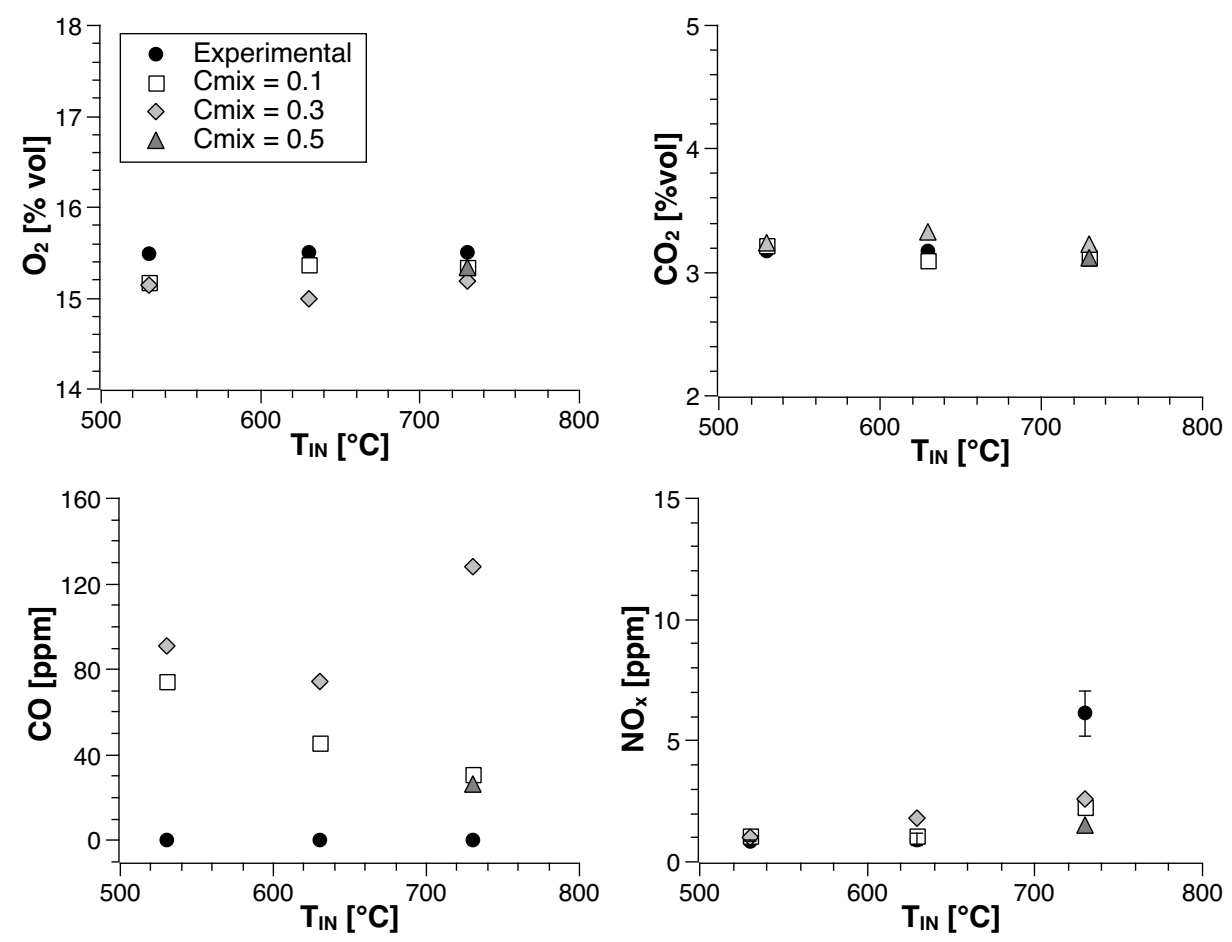

Figure 17. Comparison between measured and computed values of $\mathrm{O}_{2}(\% \mathrm{vol}), \mathrm{CO}_{2}(\% \mathrm{vol}), \mathrm{CO}(\mathrm{ppm})$, and $\mathrm{NO}_{\mathrm{x}}(\mathrm{ppm})$ concentrations in the exhaust gas for different values of the mixing timescale constant $\mathrm{C}_{m i x}$, and for different values of the air inlet temperature. $\lambda=3.5$. KEE58 kinetic mechanism.
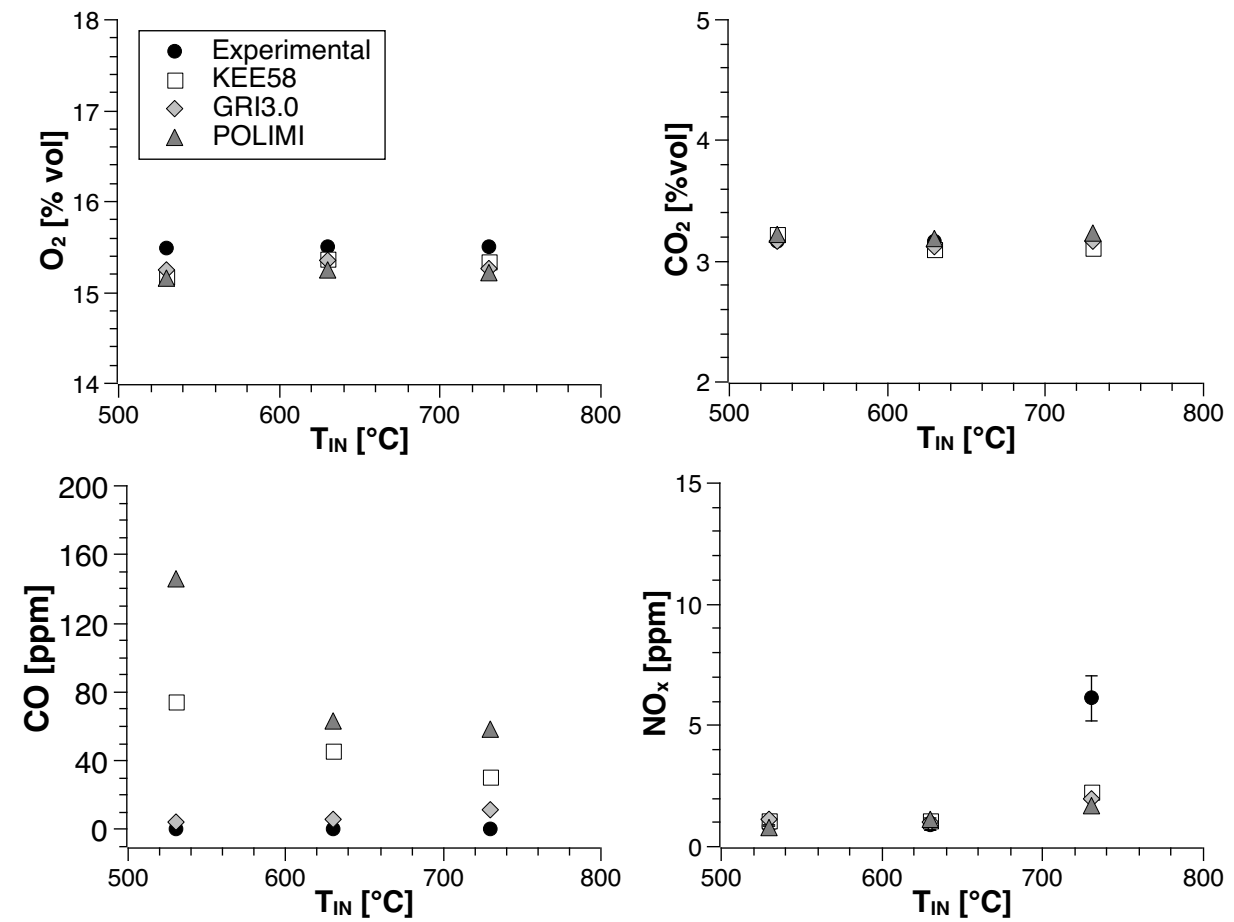

Figure 18. Comparison between measured and computed values of $\mathrm{O}_{2}(\% \mathrm{vol}), \mathrm{CO}_{2}(\% \mathrm{vol}), \mathrm{CO}(\mathrm{ppm})$, and $\mathrm{NO}_{\mathrm{x}}(\mathrm{ppm})$ concentrations in the exhaust gas for different kinetic mechanisms at different air inlet temperatures. $\lambda=3.5$. 

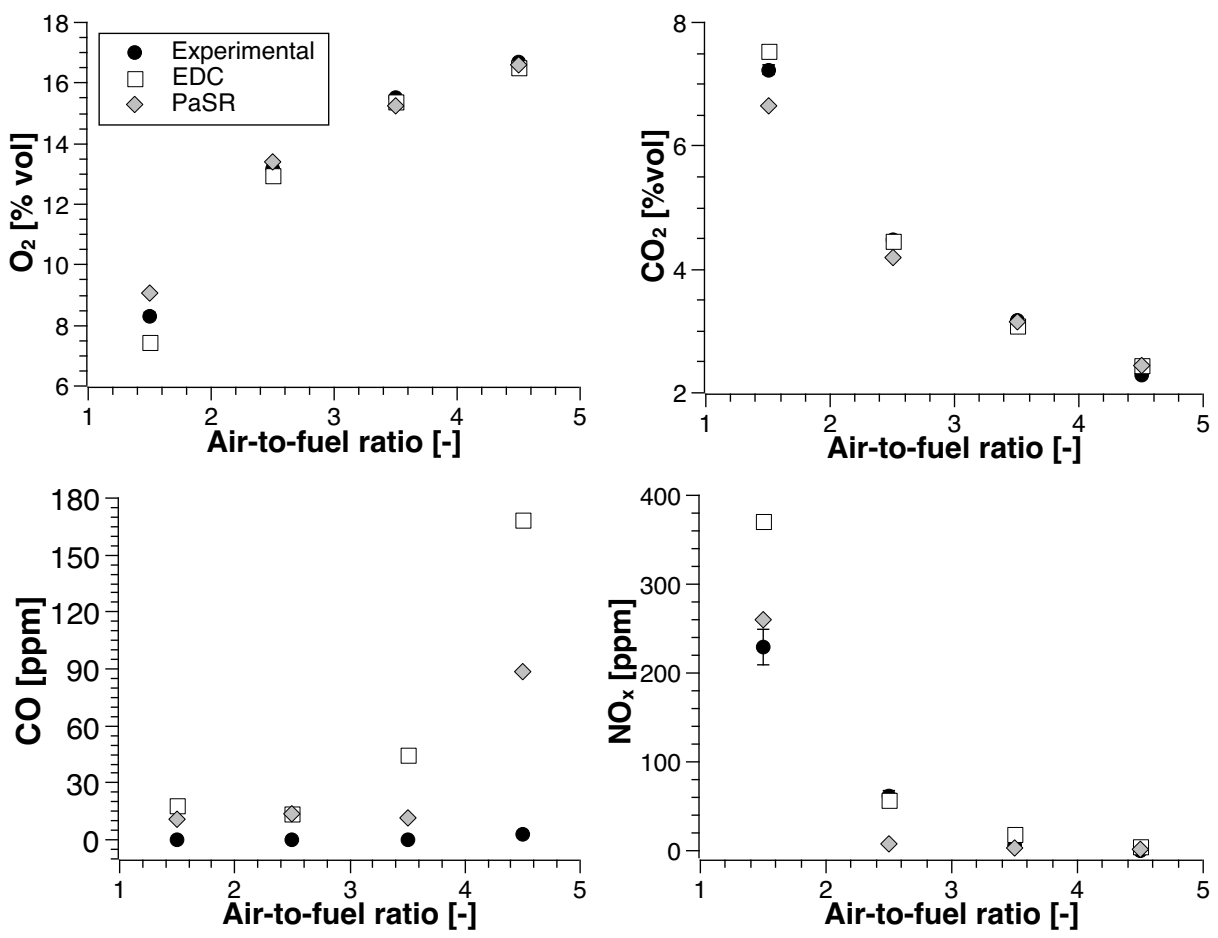

Figure 19. Comparison between measured values of $\mathrm{O}_{2}$ (\% vol), $\mathrm{CO}_{2}(\% \mathrm{vol}), \mathrm{CO}(\mathrm{ppm})$, and $\mathrm{NO}_{\mathrm{x}}$ (ppm) concentrations in the exhaust gas and those computed with EDC and PaSR combustion models for different air-to-fuel ratios. Air inlet temperature $730^{\circ} . \lambda=3.5$. GRI3.0 kinetic mechanism.

\subsection{Biogas}

To complete the investigation of the biogas combustion, numerical simulations were carried out for the runs at air inlet temperature $700{ }^{\circ} \mathrm{C}$. The combustion model was the Eddy Dissipation Concept. The comparison of the outlet temperature measured experimentally and computed numerically is reported in Figure 20. The model showed a good agreement with the experimental data, especially for the cases $\lambda=2.55$ and $\lambda=2.33$. A slight discrepancy can be noticed for the case $\lambda=1.67$. However, the computed value falls within the uncertainty on the experimental measure. It is possible to notice that the model yields an underprediction of the temperature on the outlet, which may be due to an overestimation of the computed heat losses towards the exterior. Figure 21 shows the comparison between the measured and computed concentrations of $\mathrm{O}_{2}, \mathrm{CO}_{2}, \mathrm{CO}$ and $\mathrm{NO}_{\mathrm{x}}$ in the exhaust gases for different values of $\lambda$. The computed values of $\mathrm{O}_{2}$ and $\mathrm{CO}_{2}$ are in good agreement with the measured ones, for all three $\lambda$ values. In this case as well, $\mathrm{CO}$ predictions show a large deviation from the experimental evidence. As explained before, this may be due both to the overestimation of temperature fluctuations and to the kinetic mechanism.

The $\mathrm{NO}_{\mathrm{x}}$ predictions match well the experimental data, especially for $\lambda=2.55$ and $\lambda=2.33$. A larger deviation can be noticed for $\lambda=1.67$. In this case, the model underestimated the $\mathrm{NO}_{\mathrm{x}}$ concentration. However, it is worth mentioning that the experimental value is characterized by an uncertainty of $\pm 50 \mathrm{ppm}$ plus $\pm 5 \mathrm{ppm}$ due to the accuracy of the instrument. The discrepancy between model and experiments may be due to the fact that the temperature inside the chamber is underestimated by the model. Indeed, it is possible that for the case $\lambda=1.67$, hot spots were present inside the chamber. This resulted in some instabilities that were noticed during operations. Those considerations are corroborated by Figure 22, which shows the temperature distribution inside the chamber predicted with the numerical model. The distribution looks quite uniform for $\lambda=2.55$ and $\lambda=2.33$, while for $\lambda=1.67$ it is evident that quite high temperatures are reached inside the chamber. The maximum temperatures are $1935 \mathrm{~K}, 1724 \mathrm{~K}$, and $1659 \mathrm{~K}$ for $\lambda=1.67, \lambda=2.33$ and $\lambda=2.55$, 
respectively. Those temperatures are lower than the case methane, shown in Section 4.1, because of the lower heating value of the biogas when compared with methane.

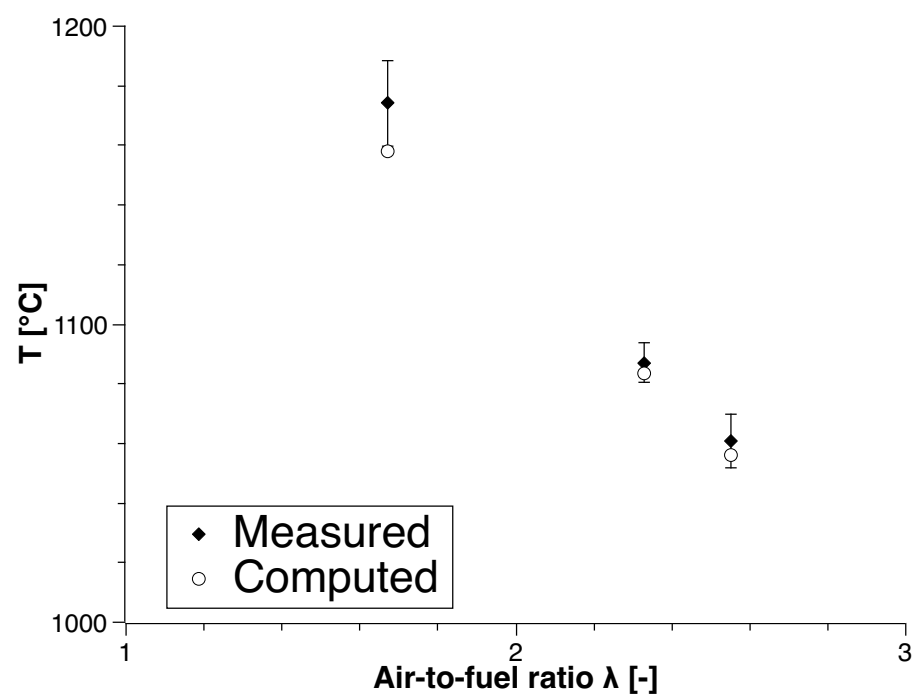

Figure 20. Comparison between the exhaust gases temperature $\left({ }^{\circ} \mathrm{C}\right)$ measured and the one predicted with the numerical model for different values of air-to-fuel ratios and different air inlet temperatures.
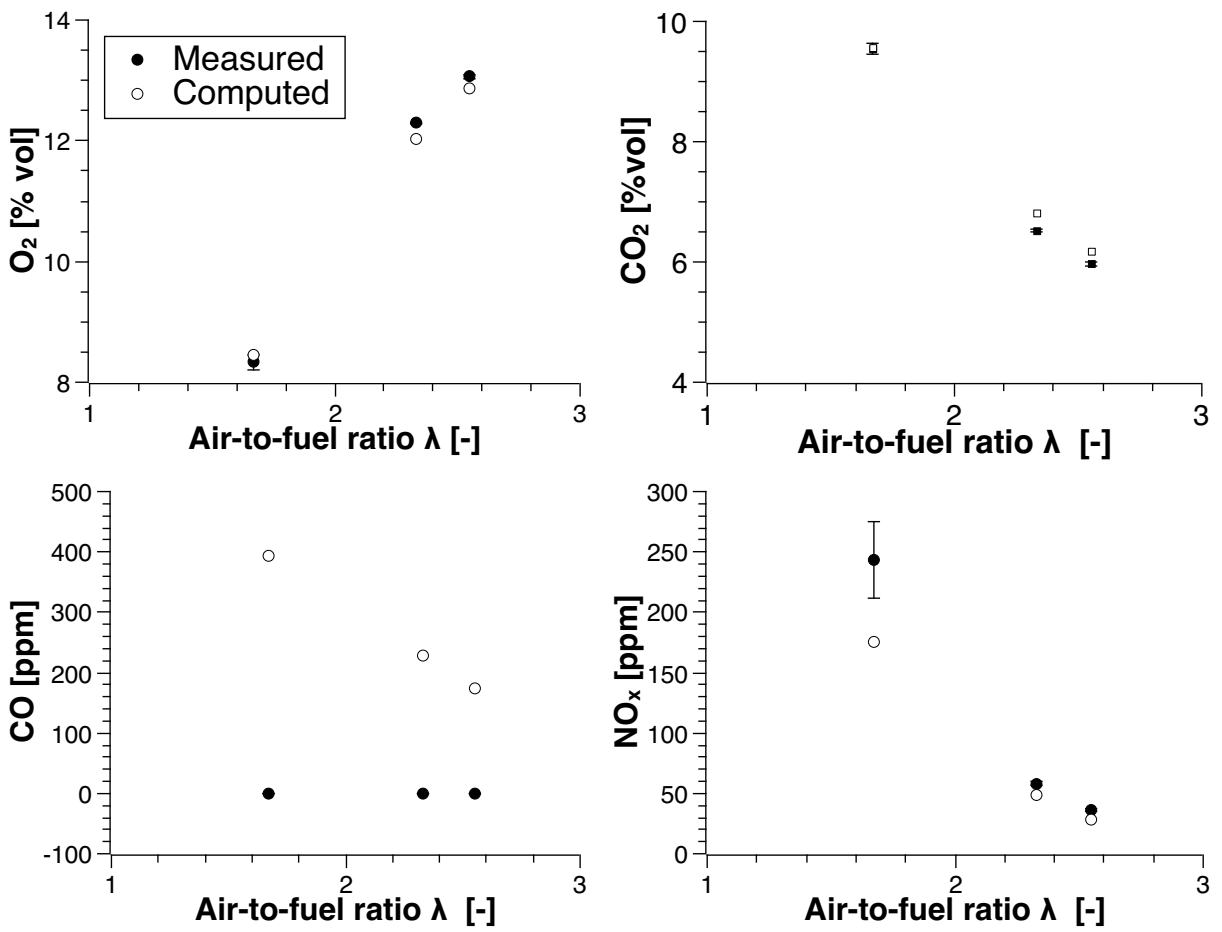

Figure 21. Comparison between the concentrations of $\mathrm{O}_{2}$ (\% vol), $\mathrm{CO}_{2}\left(\%\right.$ vol), $\mathrm{CO}$ (ppm), and $\mathrm{NO}_{\mathrm{x}}$ (ppm) measured and the one predicted with the numerical model for different values of air-fuel equivalence ratios. Air inlet temperature $700^{\circ} \mathrm{C}$. 


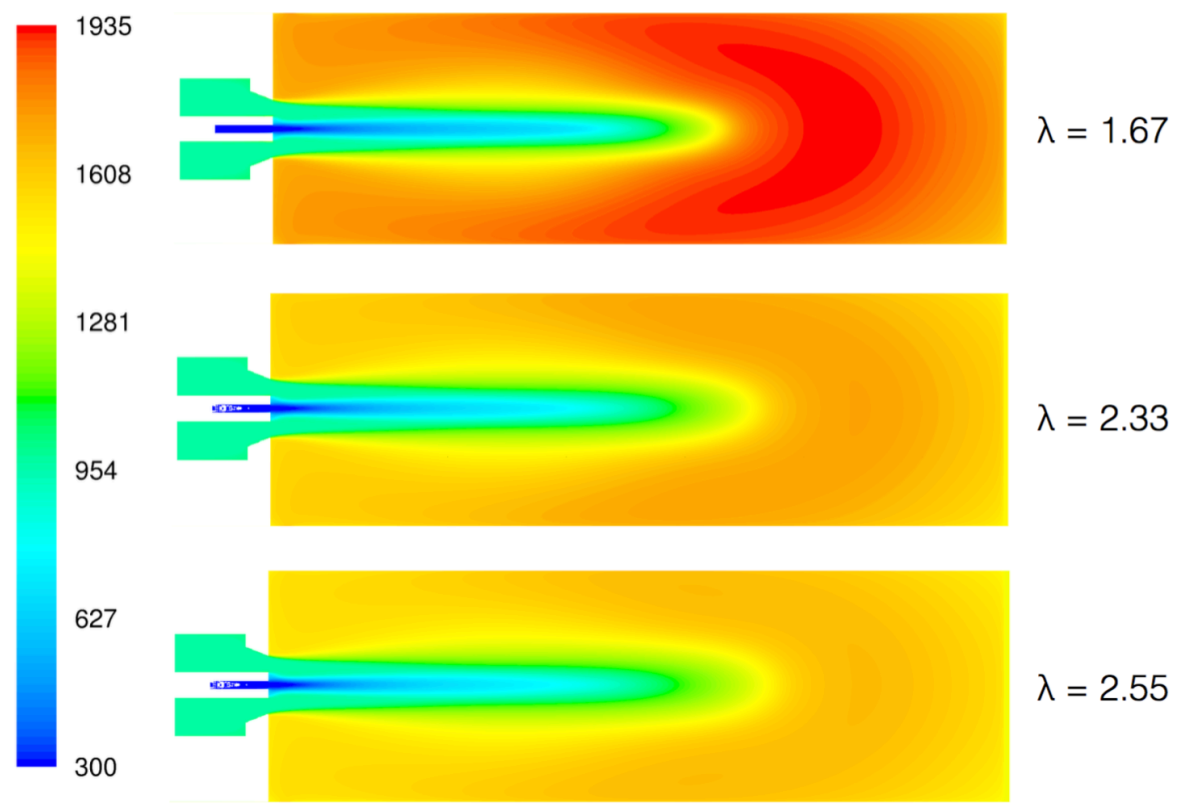

Figure 22. Temperature distribution $(\mathrm{K})$ inside the combustion chamber, for different values of air-fuel equivalence ratios. Air inlet temperature $700{ }^{\circ} \mathrm{C}$. EDC-GRI3.0 numerical model.

For the run $\lambda=2.55$ at $700{ }^{\circ} \mathrm{C}$, an analysis on the effect of the kinetic mechanism was also performed. As for the case methane, three mechanisms were tested: KEE58, GRI3.0, and a reduced mechanism based on POLIMI. Figure 23 shows the comparison between the outlet temperature and the $\mathrm{CO}$ and the $\mathrm{NO}_{\mathrm{x}}$ emissions in the exhaust gases measured and computed with the three different kinetic schemes. It is possible to notice that the exhaust gases temperature was predicted similarly by the three mechanisms. The relative error is in the order of 3\% for all three mechanisms. On the other hand, the KEE58 led to an overestimation both of the $\mathrm{CO}$ and $\mathrm{NO}_{\mathrm{x}}$ emissions. GRI3.0 and POLIMI both better predicted the $\mathrm{CO}$ emissions, even though a large discrepancy between the computed and measured value can still be noticed. As explained in Section 4.1, the EDC approach may lead to overestimations of some of the minor species, such as CO. Finally, it is possible to notice that the GRI3.0 is the mechanism that allows the best prediction of the $\mathrm{NO}_{\mathrm{x}}$ emissions. The relative error was in the order of $40 \%$ for KEE58 and POLIMI, while for the GRI3.0 the relative error was $2 \%$.
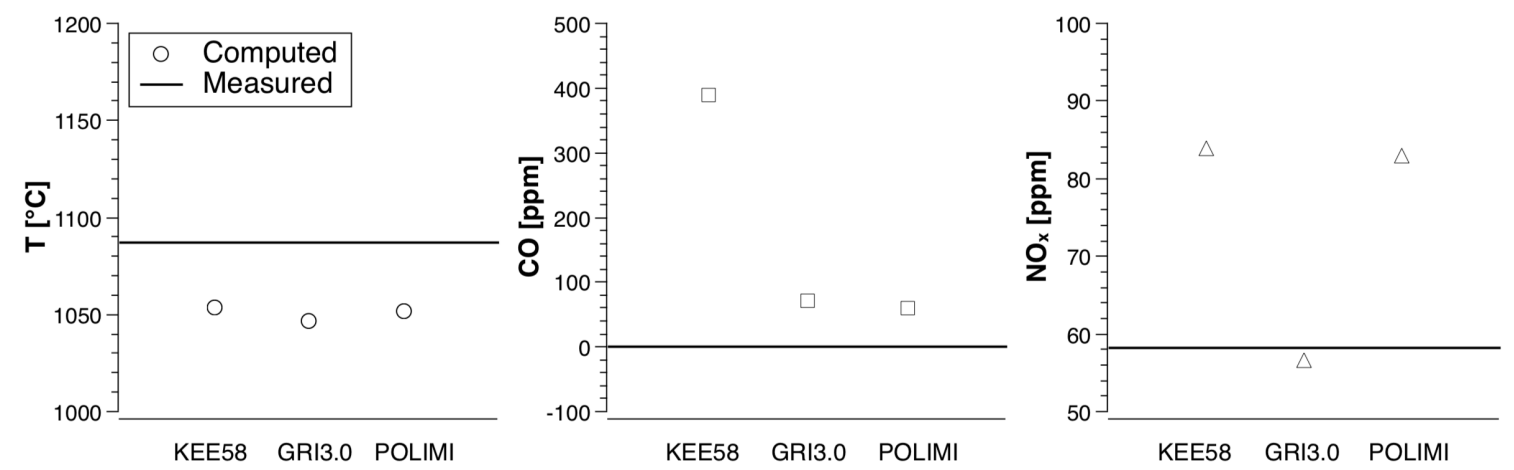

Figure 23. Comparison between the exhaust gases temperature $\left({ }^{\circ} \mathrm{C}\right)$, the $\mathrm{CO}(\mathrm{ppm})$, and $\mathrm{NO}_{\mathrm{x}}(\mathrm{ppm})$ measured and the one predicted with different kinetic schemes. $\lambda=2.55$. Air inlet temperature $700{ }^{\circ} \mathrm{C}$.

To improve the $\mathrm{CO}$ predictions, the PaSR model was also tested. The case analyzed was $\lambda=2.55$ and air inlet temperature $700{ }^{\circ} \mathrm{C}$. Three values of the mixing timescale constant $\mathrm{C}_{\text {mix }}$ were tested $(0.1$, 0.3 , and 0.5). On the basis of the the results shown in Figure 23, the kinetic mechanism employed 
was the GRI3.0. The results are shown in Figure 24. It is possible to notice that the prediction of CO emissions drastically improved when the PaSR was used. For all the values of $\mathrm{C}_{\text {mix }}$ tested, the values of $\mathrm{CO}$ are much closer to the experimental evidence than the ones obtained with the EDC. The best results were obtained for $\mathrm{C}_{m i x}=0.3$ for which $\mathrm{CO}$ is $18 \mathrm{ppm}$.

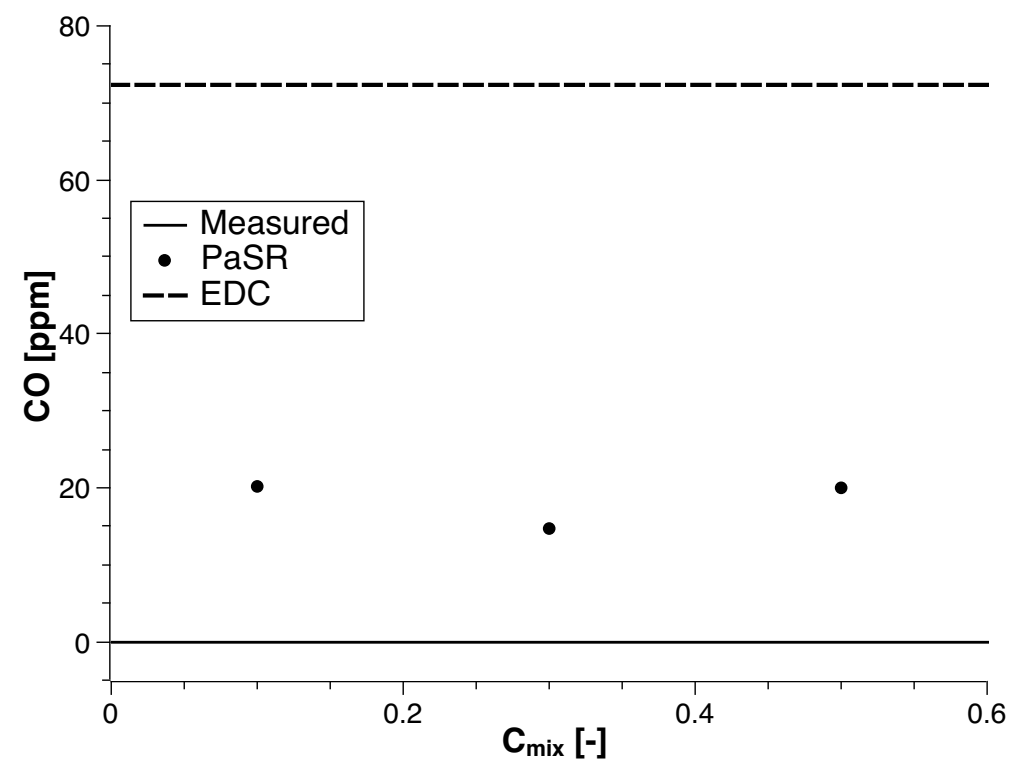

Figure 24. Comparison between the $\mathrm{CO}$ ( $\mathrm{ppm}$ ) measured, the ones predicted with the EDC model and the ones predicted with the PaSR combustion model for different values of $C_{\text {mix }} . \lambda=2.55$. Air inlet temperature $700{ }^{\circ} \mathrm{C}$.

The $\mathrm{NO}_{\mathrm{x}}$ emissions, for all the cases discussed, were calculated in post-processing. This means that the equations to calculate the $\mathrm{NO}_{\mathrm{x}}$ were solved separately, after that the equations for flow, energy, and gas-phase oxidation converged. Indeed, it is possible to decouple the $\mathrm{NO}_{\mathrm{x}}$ calculations because the timescales of certain formation routes, especially thermal NO, are larger (up to three times) that of the timescales of the fuel oxidation. In addition, minor species, such as $\mathrm{NO}_{\mathrm{x}}$, have only a marginal effect on the main combustion process and consequently do not affect the overall temperature and flow field [50]. To confirm the effectiveness of this approach, for the run $\lambda=2.55$ at $700{ }^{\circ} \mathrm{C} \mathrm{NO}_{x}$ was calculated as the same time as the gas phase oxidation, by means of the reactions included in the full GRI3.0 mechanism. In this case, the $\mathrm{NO}_{\mathrm{x}}$ was estimated at $4 \mathrm{ppm}$ with respect to the $58 \mathrm{ppm}$ measured. The same mechanism, the GRI3.0 provided $57 \mathrm{ppm}$ when post-processing was adopted. The large underestimation is most likely due to the wrong estimation of the thermal NO which are not negligible in this case, as a result of the higher temperatures as shown in Section 3.2. This confirms that post-processing calculations represent a good approach to estimate $\mathrm{NO}_{\mathrm{x}}$ emissions.

\section{Conclusions}

The present work describes the performances of a combustion chamber for a mGT operating in the MILD regime. It has been shown that the combustion chamber is stable and performs well in terms of emissions for a wide range of air inlet temperatures and air-to-fuel ratio values. Except when close to stoichiometric conditions, both $\mathrm{CO}$ and $\mathrm{NO}_{\mathrm{x}}$ emissions were extremely low for all air-to-fuel ratios and air inlet temperatures. The chamber performed best at its nominal operating condition, i.e., $\lambda=3.5$ and air inlet temperature $730^{\circ} \mathrm{C}$. In this case, $\mathrm{CO}$ was $0 \mathrm{ppm}$ and $\mathrm{NO}_{\mathrm{x}}$ was $6.2 \mathrm{ppm}$.

The chamber proved to be fuel flexible. Indeed, ignition and stable combustion were achieved when biogas was burnt. As a result of a calibration error on the gas flow meter, it was not possible to investigate the conditions of the design point $(\lambda=3.5)$. Three other conditions were examined, 
characterized by lower values of $\lambda$, closer to stoichiometric conditions. Consequently, higher values of $\mathrm{NO}_{x}$ emissions were found as are result of the lower air excess and to the higher temperatures.

The numerical model employed to describe the combustor performed quite well both for methane and biogas. In particular, for methane the PaSR combustion model proved to be the best choice to predict both minor species as $\mathrm{CO}$ more accurately and cases with lower reactivity that were not possible to model using the EDC. For the biogas, it was shown that the GRI3.0 allows for the chamber's behavior to be properly modeled.

Author Contributions: Conceptualization, V.F., R.N. and M.D.; Methodology, V.F., M.D. and A.P.; Experimental data acquisition, V.F., A.G. and M.R.; Numerical investigation, V.F.; Writing-Original Draft Preparation, V.F.; Writing-Review \& Editing A.P.; Supervision, M.D. and A.P.; Project Administration M.D. and A.P.; Funding Acquisition M.D.

Conflicts of Interest: The authors declare no conflict of interest.

\section{Abbreviations}

The following abbreviations are used in this manuscript:

$\begin{array}{ll}\text { CFD } & \text { Computational Fluid Dynamic } \\ \text { EDC } & \text { Eddy Dissipation Concept } \\ \text { HiTAC } & \text { High Temperature Air Combustion } \\ \text { JHC } & \text { Jet in Hot Coflow } \\ \text { MILD } & \text { Moderate and Intense Low-Oxygen } \\ \text { mGT } & \text { Micro Gas Turbine } \\ \text { PaSR } & \text { Partially Stirred Reactor } \\ \text { PDF } & \text { Probability Density Function } \\ \text { TPDF } & \text { Transorted Probability Density Function } \\ \text { UDF } & \text { User Defined Function }\end{array}$

\section{References}

1. Onovwiona, H.; Ugursal, V. Residential cogeneration systems: review of the current technology. Renew. Sustain. Energy Rev. 2006, 10, 389-431. [CrossRef]

2. Abagnale, C.; Cameretti, M.; De Robbio, R.; Tuccillo, R. Thermal Cycle and Combustion Analysis of a Solar-Assisted Micro Gas Turbine. Energies 2017, 10, 773. [CrossRef]

3. Khidr, K.; Eldrainy, Y.; EL-Kassaby, M. Towards lower gas turbine emissions: Flameless distributed combustion. Renew. Sustain. Energy Rev. 2017, 67, 1237-1266. [CrossRef]

4. Cavaliere, A.; de Joannon, M. Mild combustion. Prog. Energy Combust. Sci. 2004, 30, 329-366. [CrossRef]

5. Wünning, J.; Wünning, J. Flameless oxidation to reduce thermal NO-formation. Prog. Energy Combust. Sci. 1997, 23, 81-94. [CrossRef]

6. Gupta, A. Thermal characteristics of gaseous fuel flames using high temperature air. J. Eng. Gas Turbines Power 2004, 126, 9-19. [CrossRef]

7. Kumar, S.; Paul, P.; Mukunda, H. Studies on a new high-intensity low-emission burner. Proc. Combust. Inst. 2002, 29, 1131-1137. [CrossRef]

8. Dally, B.; Riesmeier, E.; Peters, N. Effect of fuel mixture on moderate and intense low oxygen dilution combustion. Combust. Flame 2004, 137, 418-431. [CrossRef]

9. Duwig, C.; Stankovic, D.; Fuchs, L.; Li, G.; Gutmark, E. Experimental and numerical study of flameless combustion in a model gas turbine combustor. Combust. Sci. Technol. 2007, 180, 279-295. [CrossRef]

10. Arghode, V.; Gupta, A. Development of high intensity CDC combustor for gas turbine engines. Appl. Energy 2011, 88, 963-973. [CrossRef]

11. Arghode, V.; Gupta, A.; Bryden, K. High intensity colorless distributed combustion for ultra low emissions and enhanced performance. Appl. Energy 2012, 92, 822-830. [CrossRef]

12. Zornek, T.; Monz, T.; Aigner, M. Performance analysis of the micro gas turbine Turbec T100 with a new FLOX-combustion system for low calorific fuels. Appl. Energy 2015, 159, 276-284. [CrossRef] 
13. Seliger, H.; Huber, A.; Aigner, M. Experimental Investigation of a FLOX®-Based Combustor for a Small-Scale Gas Turbine Based CHP System Under Atmospheric Conditions. In Proceedings of the ASME Turbo Expo 2015: Turbine Technical Conference and Exposition, Montreal, QC, Canada, 15-19 June 2015; ASME Paper No. GT2015-43094; 2015.

14. Choi, G.; Katsuki, M. Advanced low NOx combustion using highly preheated air. Energy Convers. Manag. 2001, 42, 639-652. [CrossRef]

15. Sabia, P.; de Joannon, M.; Fierro, S.; Tregrossi, A.; Cavaliere, A. Hydrogen-enriched methane mild combustion in a well stirred reactor. Exp. Thermal Fluid Sci. 2007, 31, 469-475. [CrossRef]

16. Hosseini, S.; Wahid, M. Biogas utilization: experimental investigation on biogas flameless combustion in lab-scale furnace. Energy Convers. Manag. 2013, 74, 426-432. [CrossRef]

17. Colorado, A.; Herrera, B.; Amell, A. Performance of a flameless combustion furnace using biogas and natural gas. Bioresour. Technol. 2010, 101, 2443-2449. [CrossRef] [PubMed]

18. Chen, S.; Zheng, C. Counterflow diffusion flame of hydrogen-enriched biogas under MILD oxy-fuel condition. Int. J. Hydrogen Energy 2011, 36, 15403-15413. [CrossRef]

19. Galletti, C.; Parente, A. Tognotti, L. Numerical and experimental investigation of a mild combustion burner. Combust. Flame 2007, 151, 649-664. [CrossRef]

20. Isaac, B.; Parente, A.; Galletti, C.; Thornock, J.; Smith, P.; Tognotti, L. A novel methodology for chemical time scale evaluation with detailed chemical reaction kinetics. Energy Fuels 2013, 27, 2255-2265. [CrossRef]

21. Ghadamgahi, M.; Ölund, P.; Andersson, N.; Jönsson, P. Numerical study on the effect of lambda value (oxygen/fuel ratio) on temperature distribution and efficiency of a flameless oxyfuel combustion system. Energies 2017, 10, 338. [CrossRef]

22. Wang, H.; Zhou, H.; Ren, Z.; Law, C. Transported PDF simulation of turbulent CH 4/H 2 flames under MILD conditions with particle-level sensitivity analysis. Proc. Combust. Inst. 2018, in press. [CrossRef]

23. Lee, J.; Jeon, S.; Kim, Y. Multi-environment probability density function approach for turbulent $\mathrm{CH} 4 / \mathrm{H} 2$ flames under the MILD combustion condition. Combust. Flame 2015, 162, 1464-1476. [CrossRef]

24. Magnussen, B. On the structure of turbulence and a generalized eddy dissipation concept for chemical reaction in turbulent flow. In Proceedings of the 19th Aerospace Sciences Meeting, St. Louis, MO, USA, 12-15 January 1981; p. 42.

25. Gran, I.; Magnussen, B. A numerical study of a bluff-body stabilized diffusion flame. Part 2. Influence of combustion modeling and finite-rate chemistry. Combust. Sci. Technol. 1996, 119, 191-217. [CrossRef]

26. Magnussen, B.F. The Eddy Dissipation Concept-A Bridge Between Science and Technology. In Proceedings of the ECCOMAS Thematic Conference on Computational Combustion, Lisbon, Portugal, 21-24 June 2005; pp. 21-24.

27. Fortunato, V.; Galletti, C.; Tognotti, L.; Parente, A. Influence of modelling and scenario uncertainties on the numerical simulation of a semi-industrial flameless furnace. Appl. Thermal Eng. 2015, 76, 324-334. [CrossRef]

28. Bösenhofer, M.; Wartha, E.; Jordan, C.; Harasek, M. The Eddy Dissipation Concept-Analysis of Different Fine Structure Treatments for Classical Combustion. Energies 2018, 11, 1902. [CrossRef]

29. Chomiak, J. Combustion A Study in Theory, Fact and Application; Abacus Press/Gorden and Breach Science Publishers: New York, NY, USA, 1990.

30. Li, Z.; Cuoci, A.; Sadiki, A.; Parente, A. Comprehensive numerical study of the Adelaide Jet in Hot-Coflow burner by means of RANS and detailed chemistry. Energy 2017, 139, 555-570. [CrossRef]

31. Ferrarotti, M.; Li, Z.; Parente, A. On the role of mixing models in the simulation of MILD combustion using finite-rate chemistry combustion models. Proc. Combust. Inst. 2018, in press. [CrossRef]

32. Fenimore, C. Formation of nitric oxide in premixed hydrocarbon flames. In Proceedings of the International Symposium on Combustion, Los Angeles, CA, USA, 5-7 October 1971; Volume 13, pp. 373-380.

33. Malte, P.; Pratt, D. Measurement of atomic oxygen and nitrogen oxides in jet-stirred combustion. In Proceedings of the International Symposium on Combustion, Tokyo, Japan, 25-31 August 1974; Volume 15, pp. 1061-1070.

34. Konnov, A.; Colson, G.; De Ruyck, J. The new route forming NO via NNH. Combust. Flame 2000, 121, 548-550. [CrossRef]

35. Fortunato, V.; Mosca, G.; Lupant, D.; Parente, A. Validation of a reduced NO formation mechanism on a flameless furnace fed with H2-enriched Low Calorific Value fuels. Appl. Thermal Eng. 2018, 144, 877-889. [CrossRef] 
36. Delanaye, M.; Giraldo, A.; Nacereddine, R.; Rouabah, M.; Fortunato, V.; Parente, A. Development of a Recuperated Flameless Combustor for an Inverted Brayton Cycle Microturbine Used in Residential Micro-CHP. In Proceedings of the ASME Turbo Expo 2017: Turbomachinery Technical Conference and Exposition, Charlotte, NC, USA, 26-30 June 2017.

37. Fortunato, V.; Henrar, E.; Delanaye, M.; Parente, A. An optimization-based approach for the development of a combustion chamber for residential micro gasturbine applications. Chem. Eng. Trans. 2015, 43, 2113-2118.

38. Launder, B.; Spalding, D. The numerical computation of turbulent flows. Comput. Methods Appl. Mech. Eng. 1974, 3, 269-289. [CrossRef]

39. Bowman, C.; Hanson, R.; Davidson, D.; Gardiner, J.W.; Lissianski, V.; Smith, G.; Golden, D.; Frenklach, M.; Goldenberg, M. GRI-Mech 2.11. 1995. Available online: http://www.me.berkeley.edu/gri-mech (accessed on 30 September 2018).

40. Morse, A. Axisymmetric Free Shear Flows with and without Swirl. Ph.D. Thesis, University of London, London, UK, 1980.

41. Pope, S. Computationally efficient implementation of combustion chemistry using in situ adaptive tabulation. Combust. Theory Model. 1997, 1, 41-63. [CrossRef]

42. Bilger, R.; Stårner, S.; Kee, R. On reduced mechanisms for methane air combustion in nonpremixed flames. Combust. Flame 1990, 80, 135-149. [CrossRef]

43. Smith, G.; Golden, D.; Frenklach, M.; Moriarty, N.; Eiteneer, B.; Goldenberg, M.; Bowman, C.; Hanson, R.; Song, S.; Gardiner, J.W.; et al. GRI-Mech 3.0; 1999; Volume 51, p. 55. Available online: http:/ / www.me.berkeley.edu/gri_mech (accessed on 30 September 2018).

44. Stagni, A.; Frassoldati, A.; Cuoci, A.; Faravelli, T.; Ranzi, E. Skeletal mechanism reduction through species-targeted sensitivity analysis. Combust. Flame 2016, 163, 382-393. [CrossRef]

45. Ranzi, E.; Sogaro, A.; Gaffuri, P.; Pennati, G.; Faravelli, T. A wide range modeling study of methane oxidation. Combust. Sci. Technol. 1994, 96, 279-325. [CrossRef]

46. Westenberg, A. Kinetics of NO and CO in lean, premixed hydrocarbon-air flames. Combust. Sci. Technol. 1971, 4, 59-64. [CrossRef]

47. De Soete, G. Overall reaction rates of $\mathrm{NO}$ and $\mathrm{N}_{2}$ formation from fuel nitrogen. In Proceedings of the Symposium (International) on Combustion, Tokyo, Japan, 25-31 August 1974; Elsevier: Amsterdam, The Netherlands, 1975; Volume 15, pp. 1093-1102.

48. Peters, N. Turbulent Combustion; Cambridge University Press: Cambridge, UK, 2000.

49. Aminian, J.; Galletti, C.; Shahhosseini, S.; Tognotti, L. Key modeling issues in prediction of minor species in diluted-preheated combustion conditions. Appl. Therm. Eng. 2011, 31, 3287-3300. [CrossRef]

50. Faravelli, T.; Bua, L.; Frassoldati, A.; Antifora, A.; Tognotti, L.; Ranzi, E. A new procedure for predicting NOx emissions from furnaces. Comput. Chem. Eng. 2001, 25, 613-618. [CrossRef] 